\title{
DISTRIBUCIÓN DEL INGRESO Y CONSUMO DE ALIMENTOS: ESTRUCTURA, TENDENCIAS Y REQUERIMENTOS REDISTRIBUTIVOS A NIVEL REGIONAL
}

\author{
Nora LUSTIG \\ El Colegio de México
}

\section{Introducción ${ }^{1}$}

Es UN HECHO CONOCIDO que la desigualdad en la distribución del ingreso en México, se refleja en fuertes disparidades regionales. También es sabido que algunas de las consecuencias fundamentales de la desigual distribución del ingreso son - a nivel de las clases más pobres - los serios problemas de nutrición, ya que el nivel de ingreso de estas familias resulta insuficiente para generar un gasto en alimentos que permita cubrir las recomendaciones mínimas de calorías y proteínas. ${ }^{2}$

En este trabajo se presenta una descripción de la distribucion del ingreso a nivel nacional y regional, en función de] salario mínimo pertinente. En segundo lugar, se hace una caracterización del grupo de bajos ingresos en función de otras variables tales como la actividad y posición en la ocupación del jefe de grupo familiar, con el fin de indagar cuál es la inserción en la estructura productiva de estos grupos. En tercer lugar, se analiza la estructura y tendencias del consumo de la población más pobre en comparación con el resto, a nivel de grandes agregados de bienes y de productos alimenticios específicos. Por último, se estiman los requerimientos redistributivos

\footnotetext{
1 Este trabajo cs resultado de una investigación que forma parte del conjunto de proyectos que desarrolló el Sistema Alimentario Mexicano de la Oficina de Asesores de la Piesidencia. La autora agradece la valiosa colaboración de Raúl Lcgaspi, investigador asociado del proyecto; así como la asistencia de Alicia Contreras, Magda Jan, Martha Llanos del Moral, Rubén Reséndiz y Miguel Angel Santín, en el mancjo de la cuantiosa información utilizada.

2 Esto se estima en alrededor de 2600 calorías diarias per cápita un poco más de 80 gramos de proteínas (ambos se refieren a la ingesta bruta).
} 
Cuadro 1

Dlatribucín del Ingreso y Gasto Totales, y de los Hogares y las Personas por Regiốn: 1977 (Porcentajes)

\begin{tabular}{|c|c|c|c|c|c|c|c|c|c|c|c|c|c|c|c|c|c|c|c|c|}
\hline \multirow{3}{*}{ Regibn } & \multicolumn{8}{|c|}{$0 \leq Y \leq 1 \mathrm{~S} . \mathrm{M}}$. & \multicolumn{4}{|c|}{$1 \mathrm{~s} . \mathrm{M}_{0}<Y \leq 2 \mathrm{~s} . \mathrm{M}$} & \multicolumn{4}{|c|}{$Y>2 S . M}$. & \multicolumn{4}{|c|}{ Toka1 por regín } \\
\hline & \multicolumn{4}{|c|}{ Agricola } & \multicolumn{4}{|c|}{ No AgrIcola } & \multirow[b]{2}{*}{ Ingreso } & \multirow[b]{2}{*}{ Gasto } & \multirow[b]{2}{*}{ Hogare日 } & \multirow[b]{2}{*}{$\begin{array}{l}\text { Per- } \\
\text { sonag }\end{array}$} & \multirow[b]{2}{*}{ Ingreso } & \multirow[b]{2}{*}{ Gasto } & \multirow[b]{2}{*}{ Hogarea } & \multirow[b]{2}{*}{$\begin{array}{l}\text { Per- } \\
\text { sonas }\end{array}$} & \multirow[b]{2}{*}{ Ingreso } & \multirow[b]{2}{*}{ Gasto } & \multirow[b]{2}{*}{ Hogares } & \multirow[b]{2}{*}{$\begin{array}{l}\text { Per- } \\
\text { sonas }\end{array}$} \\
\hline & Ingreso & Gasto & Hogare日 & $\begin{array}{l}\text { Por- } \\
\text { gonas }\end{array}$ & Ingreso & Gasto & Hogares & $\begin{array}{l}\text { Per- } \\
\text { gonas }\end{array}$ & & & & & & & & & & & & \\
\hline 1 & 11.39 & 9.96 & 6.69 & 6.86 & 7.28 & 7.92 & 6.25 & 5.80 & 9.60 & 10.35 & 9.03 & 9.05 & 9.67 & 9.01 & 8.43 & 8.94 & 9.57 & 9.34 & 7.82 & 8.05 \\
\hline 2 & 3.79 & 3.91 & 3.49 & 3.38 & 4.44 & 4.50 & 4.34 & 3.56 & 4.39 & 5.05 & 4.56 & 4.39 & 4.65 & 4.41 & 4.95 & 4.20 & 4.52 & 4.55 & 4.40 & 4.00 \\
\hline 3 & 11.23 & 11,83 & 10.34 & 10.47 & 9.80 & 9.85 & 10.59 & 10.45 & 10.55 & 10.62 & 11.22 & 11.08 & 10.68 & 10.37 & 11.78 & 12.41 & 10.61 & 10.49 & 11.06 & 11.27 \\
\hline 4 & 14.37 & 13.99 & 14.58 & 15.14 & 9.97 & 9.83 & 22.99 & 12.21 & 6.61 & 6.56 & 8.01 & 8.87 & 4.67 & 4.59 & 5.78 & 6.73 & 6.07 & 6.13 & 9.57 & 10.07 \\
\hline 5 & 19.72 & 19.96 & 22.30 & 23.31 & 15.00 & 14.82 & 19.02 & 20.75 & 9.85 & 9.29 & 10.68 & 11.40 & 6.08 & 6.28 & 7.29 & 8.34 & 8.41 & 8.63 & 13.85 & 14.45 \\
\hline 6 & 13.80 & 14.77 & 25.03 & 13.77 & 4.68 & 4.89 & 4.59 & 5.14 & 3.06 & 3.13 & 2.92 & 2.94 & 2.10 & 2,08 & 2.22 & 2.16 & 3.16 & 3.40 & 5.59 & 5.32 \\
\hline 7 & 8.72 & 7.71 & 9.43 & 8.88 & 4.53 & 4.26 & 5.40 & 5.09 & 5.05 & 4.89 & 6.23 & 5.80 & 4.50 & 5.02 & 5.45 & 5.16 & 4.07 & 5.10 & 6.51 & 6.14 \\
\hline 8 & 15.64 & 16.76 & 17.27 & 17.42 & 6.89 & 7.31 & 8.38 & 8.31 & 6.05 & 6.54 & 6.43 & 8.24 & 4.31 & 4.18 & 7.11 & 5.87 & 5.55 & 5.86 & 9.28 & 9.29 \\
\hline 9 & 1.34 & 1.11 & 0.87 & 0.77 & 37.41 & 36.62 & 29.44 & 28.69 & 44.84 & 43.57 & 40.92 & 38.33 & 53.34 & 54.06 & 46.99 & 46.19 & 47.24 & 46.50 & 31.93 & 31.41 \\
\hline Total & 100.00 & 100.00 & 100.00 & 100.00 & 100.00 & 200.00 & 200.00 & 200.00 & 100.00 & 100.00 & 100.00 & 100.00 & 100.00 & 100.00 & 100.00 & 100.00 & 100.00 & 100,00 & 100.00 & 100.00 \\
\hline Fuente: & $\begin{array}{l}\text { Secret } \\
\text { Hogare }\end{array}$ & La d & rogra & $i 5 n$ & esupues & esto, $c$ & roinac & & dol & atema $\mathrm{N}$ & Nacional & & $\operatorname{aac} 16:$ & & & & piret & & & \\
\hline & & & & & & & & & & & & & & & & & & & & \\
\hline
\end{tabular}


que generarían un gasto en alimentos igual al costo de la Canasta Básica de Consumo Recomendable propuesta por el Sistema Alimentario Mexicano. ${ }^{3}$

\section{Distribución del ingreso regional. Distribución del ingreso entre hogares agrícolas y no agrícolas: 1977}

En un trabajo anterior ${ }^{4}$ se demostró que los hogares que perciben un ingreso menor o igual al sálario mínimo constituyen -según la Encuesta de Ingresos y Gastos de 1977- alrededor del $45 \%$ del total de hogares, y que este grupo no alcanza a cubrir los mínimos recomendados de calorías y protefnas. Para lograr una ubicación económica y espacial más precisa del grupo de población que percibe un ingreso inferior al salario mínimo, se considerỏ indispensable conocer la distribución del ingreso a nivel regional, y las características "socioeconómicas" que permitieran inferir cuál es la inserción de esta población en el proceso de generación y captación del excedente.

En el Cuadro 1 se presenta la distribución entre regiones (nueve en total) $^{5}$ para todos los hogares; para aquellos que percibieron un ingreso mayor a dos salarios mínimos; más de uno y hasta dos, y hasta un salario mínimo, separando a este grupo en agrícola y noagrícola. En el mismo se observa que, a nivel nacional, el ingreso está muy concentrado en las áreas metropolitanas (Guadalajara, Monterrey y Ciudad de México) donde habita un $31 \%$ del total de las personas, que obtienen el $47 \%$ del ingreso total. Más aún, sólo en el caso de las áreas metropolitanas y de las regiones 1 y 2 (noroeste y noreste del país), el porcentaje de ingreso supera (levemente para estas dos últimas) al de población.

Por otra parte, la región 5 (centro del país) muestra la situación más desventajosa ya que en ella habita el $14.5 \%$ de las personas y sólo recibe el $8.4 \%$ del ingreso. Estas tendencias que presenta la distribución entre regiones a nivel nacional se presentan también, con diferencias pequeñas, a nivel de los grupos de ingreso y de los hogares agrícolas y no-agrícolas. De hecho, estos resultados no hacen más que confirmar lo que otros estudios regionales han demostrado: la mayor

3 Esta Canasta fue elaborada en el Subproyecto No. 3 del Sistema Alimentario Mexicano; este subproyecto se realizó durante el año de 1980.

4 Nora Lustig, "Distribución del ingreso y consumo de alimentos en México" Demografía y Economia, Vol. XIV, Núm. 2 (42), 1980.

5 Las entidades federativas comprendidas en cada región se especifican en el Cuadro 3. 
parte de los beneficios económicos se concentra a los grandes conglomerados urbanos. ${ }^{6}$

La distribución entre los grupos socioeconómicos por región y para el total nacional se presenta en el Cuadro 2. Como era de esperarse, el ingreso está concentrado cn el grupo que percibe más de dos salarios mínimos tanto a nivel nacional como para todas las regiones. En contraste, para el total del país, alrededor del $41 \%$ de los hogares percibe un ingreso menor o igual al salario mínimo regional correspondiente, de los cuales la mitad son hogares agricolas y la otra no-agricolas. Sin embargo, las regiones $4,5,6,7$ y 8 (que comprenden grosso modo el centro, el golfo, el sureste y la península de Yucatán) muestran un porcentaje de hogares en el grupo de hasta un salario mínimo mucho mayor $(57.7 \%, 61.6 \%, 78.9 \%, 47.14 \%$ y $57.2 \%$, respectivamente), y la mayoría de estos hogares son agrícolas. En estas mismas regiones el porcentaje de hogares en el grupo de más de dos salarios mínimos es mucho más pequeño que en el resto de las regiones; de hecho si se toma este porcentaje como indicador del grado de concentración del ingreso, las áreas metropolitanas (región 9) resultan tener la menor concentración y la región compuesta por los estados que rodean a la Ciudad de México (región 5) tienen la distribución del ingreso más concentrada.

Las consideraciones anteriores indican que, si se usa como criterio el porcentaje de hogares en el grupo de hasta un salario mínimo, las regiones más pobres son (en orden decreciente de pobreza) las regiones $6,5,4,8$ y 7: o sea; gran parte del país, con excepción del norte y de las áreas metropolitanas. ${ }^{7} \mathrm{Si}$-en cambio- se toma el ingreso per cápita mensual como un indicador de pobreza (en relación a la media nacional) la jerarquización (en orden decreciente de pobreza) es la siguiente: para los hogares agrícolas en primer lugar queda la región 5 y luego siguen la $8,4,7$ y 6 ; y para los no-agrícolas el orden es $5,4,8,6,3$ y 7 (véase Cuadro 4). En el caso de los hogares agrícolas, el ingreso per cápita de la región 5 . equivale al $49 \%$, y para los hogares no-agricolas al $56 \%$, del ingreso per cápita más alto (correspondiente a las áreas metropolitanas: región 9). Este dato es otro indicador del grado de desigualdad que prevalece en México; incluso dentro de los grupos más pobres de la población (la que percibe hasta un salario mínimo), las diferencias entre regiones son muy altas.

6 Hacemos abstracción aquí de los diferenciales de precios entre regiones, que podrían aminorar el ingreso real de los centros urbanos y por tanto su diferencia respecto al resto.

7 Esto no quiere decir que la pobreza en los cstados norteños o en las áreas metropolitanas sea inexistente, pero que - sj nos basamos en el criterio seleccionado- es menos conspicua. 
Cuadro 2

Distribucibn del Ingrese y Gasto Totales, de Hogures y Personas por Grupo Socioeconómico: 1977 (Porcentajes)

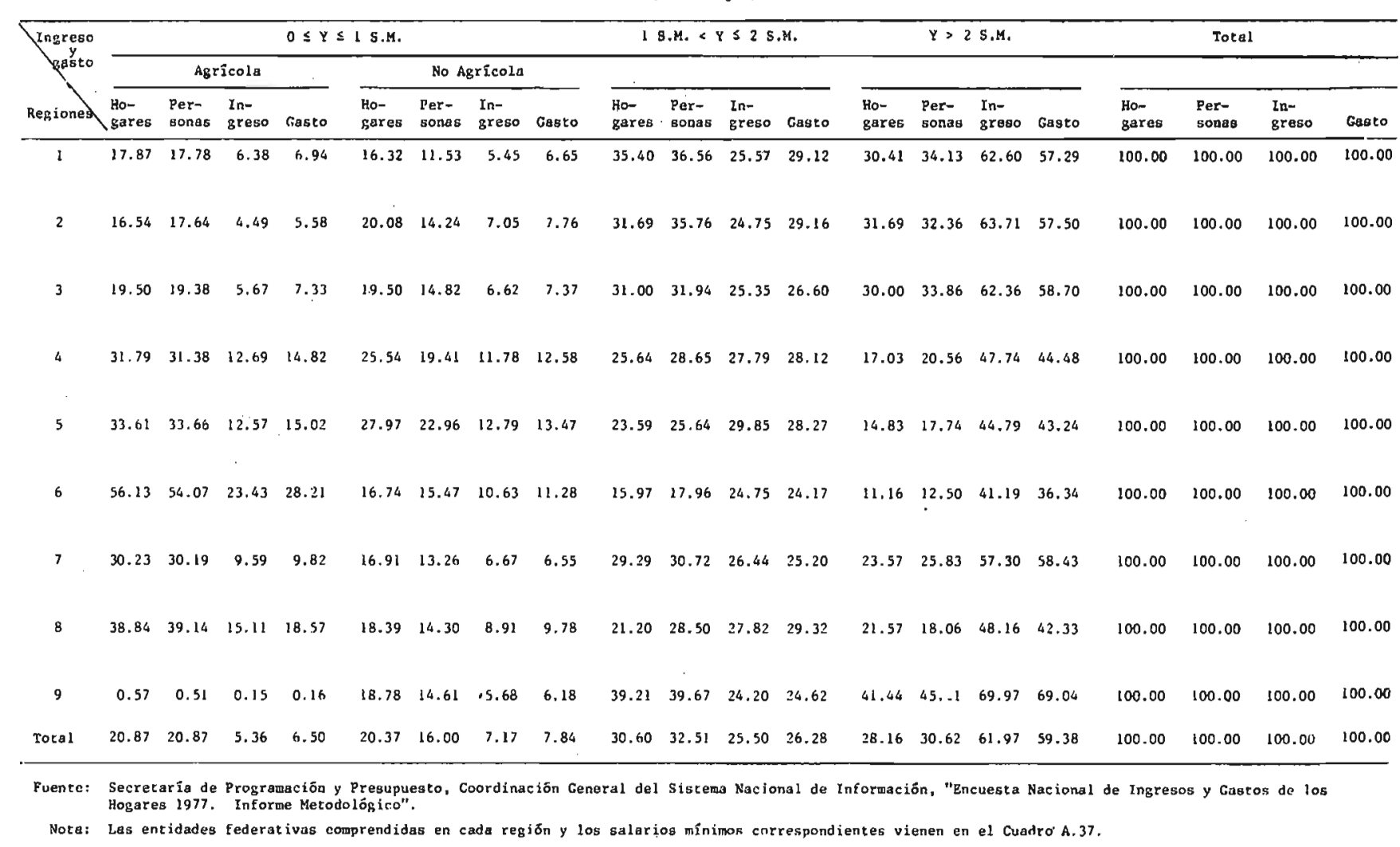


Cuadro 3

Composición de Regiones y Salario Minimo General por Region: 1977.

\begin{tabular}{|c|c|c|}
\hline Región & Entidades & $\begin{array}{c}\text { Salario Minimo } \\
\text { (pesos mensuales) }\end{array}$ \\
\hline 1 & $\begin{array}{l}\text { Baja California Norte } \\
\text { Baja California Sur } \\
\text { Sinaloa } \\
\text { Sonora } \\
\text { Nayarit }\end{array}$ & 3185.00 \\
\hline 2 & $\begin{array}{l}\text { Tamaul ipas } \\
\text { Nuevo León }\end{array}$ & 2694.00 \\
\hline 3 & $\begin{array}{l}\text { Coahuila } \\
\text { Chihuahua } \\
\text { San Luis Potosi } \\
\text { Zacatecas } \\
\text { Durango }\end{array}$ & 2684.00 \\
\hline 4 & $\begin{array}{l}\text { Aguascalientes } \\
\text { Colıma } \\
\text { Guanajuato } \\
\text { Michoacan } \\
\text { Jalisco }\end{array}$ & 2460.00 \\
\hline 5 & $\begin{array}{l}\text { Hidalgo } \\
\text { Morelos } \\
\text { Puebla } \\
\text { Querétaro } \\
\text { Tlaxcala } \\
\text { México }\end{array}$ & 2619.00 \\
\hline 6 & $\begin{array}{l}\text { Tabasco } \\
\text { Veracruz }\end{array}$ & 2933.00 \\
\hline 7 & $\begin{array}{l}\text { Campeche } \\
\text { Quintana Ron } \\
\text { Yucatín }\end{array}$ & 2367.00 \\
\hline 8 & $\begin{array}{l}\text { Chiapas } \\
\text { Guerrero } \\
\text { Oaxaca }\end{array}$ & 2357.00 \\
\hline 9 & $\begin{array}{l}\text { Areas Metropolitanas de: } \\
\text { México } \\
\text { Monterrey } \\
\text { Guadalajara }\end{array}$ & 3066.00 \\
\hline
\end{tabular}

Fuente: Secretaria de Programación y Presupuesto, Coordinacion General del Sistema Nacional de Información, Encuesta Nacional de Ingresos y Gastos de los Hogares, 1977. Informe Metodologico".

De lo anterior se desprende que las regiones con mayor pobreza en términos relativos y absolutos son las regiones 4,5 y 8 , y, en menor grado, las regiones 6 y 7 . Si se comparan estos resultados con los obtenidos en la Encuesta Nacional de Nutrición de $1979^{8}$ se observa que hay una alta coincidencia entre las zonas de déficit calórico "grave" y "regular" que arroja dicha encuesta y las regiones de mayor pobreza mencionadas. Las excepciones son Tabasco y Vera-

8 Instituto Nacional de la Nutrición. Segunda encuesta de alimentación y nutrición. Datos preliminares de primera observación del medio rural; encuesta de iulio-septiembre de 1979, México, febrero, 1980. 
Cuadro 4

Ingreso y Gasto per CSplta por Reg16n y Grupo Socloecon6mico: 1977 (pesos mensuales)

\begin{tabular}{|c|c|c|c|c|c|c|c|c|c|c|}
\hline \multirow{3}{*}{ Regibn } & \multicolumn{4}{|c|}{$0 \leq Y \leq 1$ S.M. } & \multicolumn{2}{|c|}{1 S.M. $<Y \leq 2$ S.M. } & \multicolumn{2}{|c|}{$y>2$ S.M. } & \multicolumn{2}{|c|}{ Tota1 } \\
\hline & \multicolumn{2}{|c|}{ Agricola } & \multicolumn{2}{|c|}{ No Agrícola } & \multirow[b]{2}{*}{$Y$} & \multirow[b]{2}{*}{ G } & \multirow[b]{2}{*}{$Y$} & \multirow[b]{2}{*}{ G } & \multirow[b]{2}{*}{$\mathrm{Y}$} & \multirow[b]{2}{*}{ G } \\
\hline & $Y$ & G & $Y$ & G & & & & & & \\
\hline 1 & 374.05 & 426.54 & 492.99 & 631.09 & 729.29 & 871.36 & 1912.13 & 1835.97 & 1042.56 & 1093.77 \\
\hline 2 & 252.59 & 339.96 & 490.83 & 585.55 & 686.77 & 876.42 & 1953.91 & 1910.44 & 992.24 & 1074.90 \\
\hline 3 & 241.44 & 331.79 & 368.55 & 436.16 & 655.21 & 730.67 & 1520.87 & 1521.08 & 825.61 & 877.31 \\
\hline 4 & 213.80 & 271.30 & 321.08 & 372.53 & 512.95 & 563.93 & 1228.03 & 1243.34 & 528.84 & 574.63 \\
\hline 5 & 190.53 & 251.29 & 284.38 & 330.50 & 594.33 & 621.03 & 1289.25 & 1373.25 & 510.47 & 563.27 \\
\hline 6 & 225.70 & 314.79 & 358.05 & 440.10 & 717.88 & 811.67 & 1717.17 & 1754.40 & 520.97 & 603.34 \\
\hline 7 & 221.06 & 254.98 & 386.79 & 385.79 & 598.56 & 642.93 & 1542.77 & 1772.41 & 695.54 & 783.64 \\
\hline 8 & 202.14 & 282.40 & 326.35 & 407.16 & 511.23 & 612.23 & 1396.87 & 1395.01 & 523.72 & 595.14 \\
\hline 9 & 390.82 & 422.44 & 512.80 & 590.66 & 804.78 & 866.50 & 2041.75 & 2131.82 & 1319.25 & 1395.99 \\
\hline Total & 225.19 & 293.58 & 393.25 & 462.70 & 687.90 & 762.22 & 1775.27 & 1829.07 & 864.15 & 877.15 \\
\hline
\end{tabular}
Fuente: Secretaria de Programacion y Presupuesto, Coordinaci6n Genera1. del Sistema Nacional de Informacion,
"Encuesta Nacional de Ingresos y Gastos de los Hogares, 1977. Informe Metodol6gico". Nota: Las entidades federativas comprendidas en cada region y los salarios minimos correspondientes, vienen 
cruz; calificadas por la Encuesta de Nutrición (1979) como zonas de déficit "escaso", mientras que en la .Encuesta de Ingresos y Gastos (1977) estos estados forman la región 6, incluida entre las más pobres; por otro lado, los estados de San Luis Potosí y Zacatecas aparecen con un déficit calórico "grave", mientras que en nuestros resultados forman parte de regiones más ricas. Estas divergencias pueden ser el resultado de haber agregado en una sola región (como lo hace la Encuesta de Ingresos y Gastos de 1977) a zonas muy heterogéneas (por ejemplo, los casos de Coahuila y San Luis Potosí); y también pueden ser el resultado de cambios reales en las condjciones económicas entre los dos años en que se levantó una y otra encuesta. ${ }^{9}$

En todo caso, de los planteos anteriores se desprende que para mejorar la condición de vida de los sectores más pobres de la población y hacer más igualitaria la distribución regional del ingreso, es necesario redistribuir el ingreso hacia los grupos de menores recursos de las regiones 4,5 y 8 principalmente, y, en menor grado hacia las regiones 6 y 7 .

\section{Características socioeconómicas de la población que percibe ingresos inferiores al salario mínimo}

Con el fin de caracterizar a la población que se ubica por debajo del salario mínimo según su inserción en la estructura productiva, además de considerar el nivel de ingreso, se ha calculado la frecuencia de una serie de "atributos" para los hogares entre cero y medio salario mínimo, más de medio y hasta un salario mínimo, más de uno y hasta dos y más de dos salarios mínimos; este cálculo fue realizado a nivel de las nueve regiones y del total nacional. ${ }^{10}$ Los atributos contemplados en esta caracterización son: edad promedio, educación y actividad del jefe; composición del hogar por edades; y posición en la ocupación de los miembros ocupados. Los resultados se presentan en los Cuadros 5 y 6 para el total nacional y por región, respectivamente.

A nivel nacional; el grupo de los que ganaron hasta un salario mínimo muestra que, e] $40 \%$ de los jefes declaró no tener instruc-

\footnotetext{
9 Por ejemplo, Tabasco y Veracruz pueden estar expcrimentando las consecuencias "beféficas" del auge petrolero. Para poder afirmar esto, sin embargo, se necesitan muchos más elementos que la información contenida en ambas encuestas.

10 Para el total nacional se presentan los resultados para los hogares de cero hasta un salario mínimo y no se incluye al grupo entre uno y hasta dos.
} 
Cuadro 5

Caracteristicas Socioeconomicas de los Hogares por Estrato de Inqreso

\begin{tabular}{|c|c|c|c|c|c|c|c|c|c|c|}
\hline \multirow{3}{*}{$\begin{array}{l}\text { Edad promedio del jefe del hogar } \\
\text { Nivel de instruccion del jefe del hogar }\end{array}$} & \multicolumn{2}{|c|}{$y \leq \operatorname{medio~salario~}_{\min 1 \text { mo }}^{(1)}$} & \multicolumn{2}{|c|}{$\begin{array}{l}\text { (2) } \\
\text { medio salario } \\
\text { minimo } y \leq 1 \\
\text { salario mInimo }\end{array}$} & (1) & $+(2)$ & \multicolumn{2}{|c|}{ (4) } & \multicolumn{2}{|c|}{$\begin{array}{c}\text { (5) } \\
\text { Total Naclonal }\end{array}$} \\
\hline & 50.36 & & 43.48 & & 46.92 & & 43.11 & & 45.01 & \\
\hline & & & & & & & & & & \\
\hline $\begin{array}{l}\text { Sin instruccion } \\
\text { primaria incompleta }\end{array}$ & $\begin{array}{r}1056 \\
910\end{array}$ & $\begin{array}{l}49.72 \\
42.84\end{array}$ & $\begin{array}{r}830 \\
1310\end{array}$ & $\begin{array}{l}31.74 \\
50.10\end{array}$ & $\begin{array}{l}1886 \\
2220\end{array}$ & $\begin{array}{l}39.79 \\
46.84\end{array}$ & $\begin{array}{r}907 \\
2251\end{array}$ & $\begin{array}{l}14.58 \\
36.20\end{array}$ & $\begin{array}{l}2793 \\
4471\end{array}$ & $\begin{array}{l}25.49 \\
40.80\end{array}$ \\
\hline A1 menos primaria completa & 144 & 6.78 & 449 & 17.17 & 593 & 12.51 & 3016 & 48.50 & 3609 & 32.93 \\
\hline No especificado & 14 & 0.66 & 26 & 0.99 & & 0.86 & & 0.66 & 85 & 0.78 \\
\hline Total & 2124 & 100.00 & 2615 & 100.00 & 4739 & 100.00 & 6219 & 100.00 & 10958 & 100.00 \\
\hline \multicolumn{11}{|l|}{ Actividad del jefe del horar } \\
\hline $\begin{array}{l}\text { Sin actividad } \\
\text { Agricultura }\end{array}$ & $\begin{array}{r}349 \\
1263\end{array}$ & $\begin{array}{l}16.43 \\
59.46\end{array}$ & $\begin{array}{r}308 \\
1963\end{array}$ & $\begin{array}{l}1.78 \\
36.83\end{array}$ & $\begin{array}{r}657 \\
2226\end{array}$ & $\begin{array}{l}13.86 \\
46.97\end{array}$ & $\begin{array}{l}668 \\
632\end{array}$ & $\begin{array}{r}10.74 \\
8.55\end{array}$ & $\begin{array}{l}1325 \\
2858\end{array}$ & $\begin{array}{l}12.04 \\
56.08\end{array}$ \\
\hline Ganadersa & 37 & 1.74 & 56 & 2.14 & 93 & 1.96 & 48 & 0.90 & 141 & 1.29 \\
\hline Avicultura & 6 & 0.28 & 7 & .27 & 13 & 0.27 & 6 & 0.10 & 19 & 0.17 \\
\hline Silvicultur & 10 & 0.47 & 9 & .34 & 19 & 0.40 & 6 & 0.10 & 25 & 0.23 \\
\hline $\begin{array}{l}\text { Pesca } \\
\text { Combina }\end{array}$ & $\frac{1}{4}$ & $\begin{array}{l}0.05 \\
0.19\end{array}$ & $\begin{array}{r}19 \\
9\end{array}$ & $\begin{aligned} .73 \\
.34\end{aligned}$ & $\begin{array}{l}20 \\
13\end{array}$ & $\begin{array}{l}0.42 \\
0.27\end{array}$ & $\begin{array}{l}22 \\
10\end{array}$ & $\begin{array}{l}0.35 \\
0.16\end{array}$ & $\begin{array}{l}42 \\
23\end{array}$ & $\begin{array}{l}0.38 \\
0.21\end{array}$ \\
\hline arias & 1 & & $\begin{array}{l}9 \\
1\end{array}$ & .04 & $\begin{array}{r}13 \\
2\end{array}$ & $\begin{array}{l}0.27 \\
0.04\end{array}$ & $\begin{array}{r}10 \\
3\end{array}$ & $\begin{array}{l}0.16 \\
0.05\end{array}$ & $\begin{array}{r}23 \\
5\end{array}$ & 0.21 \\
\hline ente/Especific. & 1 & & ${ }_{3}^{1}$ & .11 & 4 & 0.08 & 7 & 0.11 & 11 & 0.10 \\
\hline Extrac. Y refinación de netroloo y qas & 0 & 0.0 & 5 & .19 & 5 & 0.11 & 51 & 0.82 & 56 & 0.51 \\
\hline Extracción de minas y canteras & 7 & 0.33 & 12 & .46 & 19 & 0.40 & 18 & 0.29 & 37 & 0.34 \\
\hline ias de transformacion & 86 & 4.05 & 332 & 12.70 & 418 & 8.82 & 1380 & 22.19 & 1798 & 16.41 \\
\hline ccisn & 57 & 2.68 & 226 & 8.64 & 283 & 5.97 & 440 & 7.08 & 723 & 6.60 \\
\hline $\begin{array}{l}\text { Electr } \\
\text { Comerc }\end{array}$ & 125 & $\begin{array}{r}0.05 \\
5.89\end{array}$ & 23 & .08 & $35^{3}$ & 0.06 & $\begin{array}{r}44 \\
823\end{array}$ & 0.71 & 47 & 0.43 \\
\hline $\begin{array}{l}\text { Comerc } \\
\text { Servic }\end{array}$ & $\begin{array}{l}125 \\
138\end{array}$ & $\begin{array}{l}5.89 \\
6.50\end{array}$ & $\begin{array}{l}236 \\
258\end{array}$ & $\begin{array}{l}9.02 \\
9.87\end{array}$ & $\begin{array}{l}361 \\
396\end{array}$ & $\begin{array}{l}7.8 \\
8 .\end{array}$ & $\begin{array}{r}823 \\
1148\end{array}$ & $\begin{array}{l}3.23 \\
18.46\end{array}$ & $\begin{array}{l}1184 \\
1558\end{array}$ & $\begin{array}{l}10.80 \\
10.09\end{array}-1$ \\
\hline tes & $\begin{array}{r}138 \\
14\end{array}$ & 0.66 & $\begin{array}{r}238 \\
65\end{array}$ & 2.49 & $\begin{array}{r}390 \\
79\end{array}$ & 1. & $\begin{array}{r}1148 \\
407\end{array}$ & 6. & 1186 & $\begin{array}{r}4.44 \\
\end{array}$ \\
\hline & & 0.24 & 44 & 1. & 49 & 1. & 34 & & 394 & 3.60 \\
\hline las anteriorc & 119 & o. & 60 & 2 & 79 & 1.67 & 161 & 2.59 & 240 & 2.19 \\
\hline & 2124 & 100.00 & 2615 & 100.00 & 4739 & 100.00 & 6219 & 100.00 & 10958 & 100.00 \\
\hline \multicolumn{11}{|l|}{ Edad de } \\
\hline $\begin{array}{l}\text { Cinco años o menores } \\
\text { Cinco a doce años }\end{array}$ & $\begin{array}{l}1808 \\
1945\end{array}$ & $\begin{array}{l}19.5 \\
21.0\end{array}-0$ & $\begin{array}{l}3127 \\
3887\end{array}$ & $\begin{array}{l}20.8 \\
25.8\end{array}-10$ & 5832 & 24.0 & $\begin{array}{l}6480 \\
7649\end{array}$ & 20. & $\begin{array}{l}11413 \\
13481\end{array}$ & $\begin{array}{l}13.65 \\
22.03\end{array}$ \\
\hline Mayores de doce años & 4770 & 59.41 & 8010 & 53.32 & 13503 & 55. & 22796 & 61. & 362 & 59.32 \\
\hline Total & 9246 & 100.00 & 15024 & 100.00 & 24270 & 100.00 & 36925 & 100.00 & 61195 & 100.00 \\
\hline \multicolumn{11}{|l|}{ upacion } \\
\hline & 23 & & 43 & $i:$ & & 30 & 27 & 2. & 342 & 1.95 \\
\hline propia & 1213 & 43.3 & 1168 & 30. & 2386 & 35. & 2063 & & 4449) & 25.40 \\
\hline Trabaiz para la familia sin remuneración & 454 & 16.16 & 412 & 10.76 & 806 & 13.0 & 622 & 5. & 1488 & 8.49 \\
\hline $\begin{array}{l}\text { No sai.je o no resbonde } \\
\text { Total }\end{array}$ & $\begin{array}{r}15 \\
2809\end{array}$ & $\begin{array}{r}0.54 \\
100.00\end{array}$ & $\begin{array}{r}42 \\
3826\end{array}$ & $\begin{aligned} 1.10 \\
100.00\end{aligned}$ & $\begin{array}{r}57 \\
0655\end{array}$ & $\begin{array}{r}0.86 \\
100.00\end{array}$ & $\begin{array}{r}125 \\
10883\end{array}$ & $\begin{array}{l}1.14 \\
100.00\end{array}$ & $\begin{array}{r}182 \\
17518\end{array}$ & $\begin{array}{l}1.04 \\
100.00\end{array}$ \\
\hline & & & & & & & & & & \\
\hline
\end{tabular}

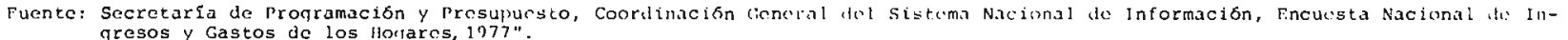

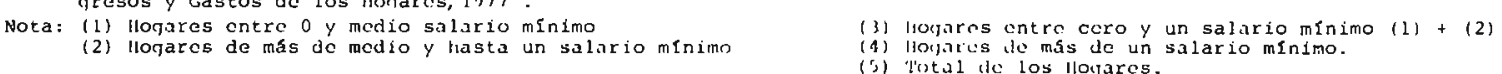


Cuadro 6

Caracteristicas socioeconomicas de los hogares, por grupo y region

\begin{tabular}{|c|c|c|c|c|c|c|c|c|c|c|c|c|}
\hline & \multicolumn{2}{|c|}{1.1} & \multicolumn{2}{|c|}{1.2} & \multicolumn{2}{|c|}{1.3} & \multicolumn{2}{|c|}{1.4} & \multicolumn{2}{|c|}{2.1} & \multicolumn{2}{|c|}{2.2} \\
\hline & Personas & 8 & Personas & 8 & Personas & 8 & Personas & 8 & Personas & 8 & Personas & 8 \\
\hline Edad promedio del jefe del hogar & 57.88 & & 44.07 & & 42.29 & & 45.14 & & 52.03 & & 45.91 & \\
\hline $\begin{array}{l}\text { Nivel de instruccion del jefe del hogar } \\
\text { Sin instruccibn } \\
\text { primaria incompleta } \\
\text { Al menos primaria completa } \\
\text { No especificado } \\
\text { Total }\end{array}$ & $\begin{array}{l}41 \\
25 \\
8 \\
0 \\
74\end{array}$ & $\begin{array}{r}55.4 \\
33.8 \\
10.8 \\
0.0 \\
100.0\end{array}$ & $\begin{array}{l}66 \\
125 \\
39 \\
0 \\
230\end{array}$ & $\begin{array}{r}28.6 \\
54.1 \\
16.9 \\
0.4 \\
100.0\end{array}$ & $\begin{array}{l}61 \\
152 \\
103 \\
1 \\
317\end{array}$ & $\begin{array}{r}19.2 \\
47.9 \\
32.5 \\
0.3 \\
100.0\end{array}$ & $\begin{array}{l}37 \\
99 \\
139 \\
2 \\
277\end{array}$ & $\begin{array}{r}13.4 \\
35.7 \\
50.2 \\
0.7 \\
100.0\end{array}$ & $\begin{array}{l}27 \\
36 \\
6 \\
1 \\
70\end{array}$ & $\begin{array}{r}38.6 \\
51.4 \\
8.6 \\
1.4 \\
100.0\end{array}$ & $\begin{array}{l}30 \\
55 \\
30 \\
1 \\
116\end{array}$ & $\begin{array}{r}25.9 \\
47.4 \\
25.9 \\
0.9 \\
100.0\end{array}$ \\
\hline $\begin{array}{l}\text { Actividad del jefe del hogar } \\
\text { Sfn actividad } \\
\text { Agricultura } \\
\text { Ganaderfa } \\
\text { Avicultura } \\
\text { Silvicultura } \\
\text { Pesca } \\
\text { Combinacion Agropecuarfa } \\
\text { Otras actividades agropecuarias } \\
\text { Acts. Agropec. Insuficiente/Especític. } \\
\text { Extrac. yefinacion de petroleo y gas } \\
\text { Extraccion de minas y canteras } \\
\text { Industrias de Transformacion } \\
\text { Constructon } \\
\text { Electricidad } \\
\text { Comercio } \\
\text { Servicfos } \\
\text { Transportes } \\
\text { Gobierno } \\
\text { No especificadas en las anteriores } \\
\text { Total }\end{array}$ & $\begin{array}{l}27 \\
29 \\
2 \\
0 \\
0 \\
0 \\
1 \\
1 \\
1 \\
0 \\
0 \\
0 \\
2 \\
0 \\
3 \\
6 \\
1 \\
0 \\
1 \\
74\end{array}$ & $\begin{array}{r}36.5 \\
39.2 \\
2.7 \\
0.0 \\
0.0 \\
0.0 \\
1.4 \\
1.4 \\
1.4 \\
0.0 \\
0.0 \\
0.0 \\
2.7 \\
0.0 \\
4.1 \\
8.1 \\
1.4 \\
0.0 \\
1.4 \\
100.0\end{array}$ & $\begin{array}{l}37 \\
104 \\
12 \\
3 \\
2 \\
5 \\
2 \\
0 \\
0 \\
0 \\
1 \\
12 \\
10 \\
0 \\
11 \\
17 \\
7 \\
4 \\
3 \\
230\end{array}$ & $\begin{array}{r}16.1 \\
45.2 \\
5.2 \\
1.3 \\
0.9 \\
2.2 \\
0.9 \\
0.0 \\
0.0 \\
0.0 \\
0.4 \\
5.2 \\
4.3 \\
0.0 \\
4.8 \\
7.4 \\
3.0 \\
1.7 \\
1.3 \\
100.0\end{array}$ & $\begin{array}{l}37 \\
83 \\
10 \\
1 \\
0 \\
4 \\
0 \\
0 \\
0 \\
0 \\
2 \\
26 \\
14 \\
1 \\
37 \\
51 \\
30 \\
18 \\
3 \\
317\end{array}$ & $\begin{array}{r}11.7 \\
26.2 \\
3.2 \\
0.3 \\
0.0 \\
1.3 \\
0.0 \\
0.0 \\
0.0 \\
0.0 \\
0.6 \\
8.1 \\
4.4 \\
0.3 \\
11.7 \\
16.1 \\
9.5 \\
5.7 \\
0.9 \\
100.0\end{array}$ & $\begin{array}{l}48 \\
54 \\
2 \\
0 \\
0 \\
3 \\
1 \\
0 \\
0 \\
0 \\
1 \\
32 \\
16 \\
1 \\
29 \\
53 \\
19 \\
14 \\
4 \\
277\end{array}$ & $\begin{array}{r}17.3 \\
19.5 \\
0.7 \\
0.0 \\
0.0 \\
1.1 \\
0.4 \\
0.0 \\
0.0 \\
0.0 \\
0.4 \\
11.5 \\
5.8 \\
0.4 \\
10.5 \\
19.1 \\
6.9 \\
5.1 \\
1.4 \\
100.0\end{array}$ & $\begin{array}{l}12 \\
41 \\
1 \\
2 \\
0 \\
1 \\
0 \\
0 \\
0 \\
0 \\
0 \\
1 \\
2 \\
0 \\
5 \\
4 \\
1 \\
0 \\
0 \\
70\end{array}$ & $\begin{array}{r}17.1 \\
58.6 \\
1.4 \\
2.9 \\
0.0 \\
1.4 \\
0.0 \\
0.0 \\
0.0 \\
0.0 \\
0.0 \\
1.4 \\
2.9 \\
0.0 \\
7.1 \\
5.7 \\
1.4 \\
0.0 \\
0.0 \\
100.0\end{array}$ & $\begin{array}{l}20 \\
37 \\
1 \\
1 \\
0 \\
0 \\
0 \\
0 \\
0 \\
2 \\
0 \\
18 \\
8 \\
0 \\
10 \\
13 \\
4 \\
0 \\
2 \\
116\end{array}$ & $\begin{array}{r}17.2 \\
31.9 \\
0.9 \\
0.9 \\
0.0 \\
0.0 \\
0.0 \\
0.0 \\
0.0 \\
1.7 \\
0.0 \\
15.6 \\
6.9 \\
0.0 \\
8.6 \\
11.2 \\
3.4 \\
0.0 \\
1.7 \\
100.0\end{array}$ \\
\hline $\begin{array}{l}\text { Edad de los miembros } \\
\text { Cinco años o menores } \\
\text { Cinco. a doce años } \\
\text { Mayores de doce años } \\
\text { Total }\end{array}$ & $\begin{array}{l}44 \\
50 \\
180 \\
274\end{array}$ & $\begin{array}{r}16.1 \\
18.2 \\
65.7 \\
100.0\end{array}$ & $\begin{array}{l}300 \\
283 \\
649 \\
1232\end{array}$ & $\begin{array}{r}24.4 \\
23.0 \\
52.7 \\
100.0\end{array}$ & $\begin{array}{l}397 \\
420 \\
1068 \\
1885\end{array}$ & $\begin{array}{r}21.1 \\
22.3 \\
56.7 \\
100.0\end{array}$ & $\begin{array}{l}229 \\
330 \\
1212 \\
1771\end{array}$ & $\begin{array}{r}12.9 \\
18.6 \\
68.4 \\
100.0\end{array}$ & $\begin{array}{l}58 \\
40 \\
164 \\
262\end{array}$ & $\begin{array}{r}22.1 \\
15.3 \\
62.6 \\
100.0\end{array}$ & $\begin{array}{l}188 \\
110 \\
327 \\
625\end{array}$ & $\begin{array}{r}30.1 \\
17.6 \\
52.3 \\
100.0\end{array}$ \\
\hline $\begin{array}{l}\text { Posici6n en la ocupacion } \\
\text { Obrero o empleado } \\
\text { Patr6n } \\
\text { Trabajador por cuenta propia } \\
\text { Trabaja para la familia sin remuneracton } \\
\text { No sabe o no responde } \\
\text { Total }\end{array}$ & $\begin{array}{l}34 \\
0 \\
29 \\
8 \\
0 \\
71\end{array}$ & $\begin{array}{r}47.89 \\
0.0 \\
40.85 \\
11.26 \\
0.0 \\
100.00\end{array}$ & $\begin{array}{l}209 \\
3 \\
64 \\
15 \\
1 \\
292\end{array}$ & $\begin{array}{r}71.58 \\
1.03 \\
21.92 \\
5.14 \\
0.33 \\
100.00\end{array}$ & $\begin{array}{l}351 \\
10 \\
92 \\
31 \\
4 \\
488\end{array}$ & $\begin{array}{r}71.93 \\
2.05 \\
18.85 \\
6.35 \\
0.82 \\
100.00\end{array}$ & $\begin{array}{l}394 \\
32 \\
88 \\
31 \\
1 \\
546\end{array}$ & $\begin{array}{r}72.16 \\
5.86 \\
16.12 \\
5.68 \\
0.18 \\
100.00\end{array}$ & $\begin{array}{l}21 \\
0 \\
43 \\
14 \\
4 \\
82\end{array}$ & $\begin{array}{r}25.61 \\
0.0 \\
52.44 \\
17.07 \\
4.88 \\
100.00\end{array}$ & $\begin{array}{l}66 \\
2 \\
71 \\
12 \\
3 \\
154\end{array}$ & $\begin{array}{r}42.83 \\
1.30 \\
46.10 \\
7.79 \\
1.98 \\
100.00\end{array}$ \\
\hline
\end{tabular}




\begin{tabular}{|c|c|c|c|c|c|c|c|c|c|c|c|c|}
\hline & \multicolumn{2}{|c|}{2.3} & \multicolumn{2}{|c|}{2.4} & \multicolumn{2}{|c|}{3.1} & \multicolumn{2}{|c|}{3.2} & \multicolumn{2}{|l|}{3.3} & \multicolumn{2}{|c|}{3.4} \\
\hline & Personas & $z$ & Personas & 8 & Personas & 8 & Personas & 8 & Personas & 8 & Personas & 8 \\
\hline Edad promedio del jefe del hogar: & 43,29 & & 43.41 & & 49.90 & & 43.73 & & 42.68 & & 44.35 & \\
\hline $\begin{array}{l}\text { Nivel de instrucciôn del jefe del hogar: } \\
\text { Sln instruccion ( }) \\
\text { Primaria incompleta (3) } \\
\text { Al menos primaria completa } \\
\text { No especificado } \\
\text { Tocal }\end{array}$ & $\begin{array}{l}31 \\
75 \\
54 \\
0 \\
160\end{array}$ & $\begin{array}{r}19.4 \\
46.9 \\
33.8 \\
0.0 \\
100.0\end{array}$ & $\begin{array}{l}11 \\
41 \\
110 \\
0 \\
162\end{array}$ & $\begin{array}{r}6.8 \\
25.3 \\
67.9 \\
0.0 \\
100.0\end{array}$ & $\begin{array}{l}86 \\
117 \\
17 \\
2 \\
222\end{array}$ & $\begin{array}{r}38.7 \\
52.7 \\
7.7 \\
0.9 \\
100.0\end{array}$ & $\begin{array}{l}70 \\
157 \\
48 \\
0 \\
275\end{array}$ & $\begin{array}{r}25.5 \\
57.1 \\
17.5 \\
0.0 \\
100.0\end{array}$ & $\begin{array}{l}49 \\
201 \\
147 \\
4 \\
401\end{array}$ & $\begin{array}{r}12.2 \\
50.1 \\
36.7 \\
1.0 \\
100.0\end{array}$ & $\begin{array}{l}29 \\
119 \\
225 \\
4 \\
377\end{array}$ & $\begin{array}{r}7.7 \\
31.6 \\
57.7 \\
1.1 \\
100.0\end{array}$ \\
\hline $\begin{array}{l}\text { Actividad del jefe del hogar: } \\
\text { Sin actividad } \\
\text { Agricultura } \\
\text { Ganaderfa } \\
\text { Avicultura } \\
\text { Silvicultura } \\
\text { Pesca } \\
\text { Combinacion Agropecuaria } \\
\text { Otras Actividades Agropecuarias } \\
\text { Acts. Agropec. Insuficiente/Especif. }(8) \\
\text { Extrac. y refinacion de petr6leo y gas (9) } \\
\text { Extraccion de minas y canteras (10) } \\
\text { Industrias de Transformaci6n } \\
\text { Construccion } \\
\text { Electricidad } \\
\text { Comercio } \\
\text { Servicios } \\
\text { Transportes } \\
\text { Gobierno } \\
\text { No especificadas en las anteriores } \\
\text { Total }\end{array}$ & $\begin{array}{l}23 \\
37 \\
3 \\
0 \\
0 \\
0 \\
1 \\
0 \\
0 \\
0 \\
0 \\
28 \\
13 \\
0 \\
29 \\
15 \\
4 \\
6 \\
1 \\
160\end{array}$ & $\begin{array}{r}14.4 \\
23.1 \\
1.9 \\
0.0 \\
0.0 \\
0.0 \\
0.6 \\
0.0 \\
0.0 \\
0.0 \\
0.0 \\
17.4 \\
8.1 \\
0.0 \\
18.1 \\
9.4 \\
2.5 \\
3.7 \\
0.6 \\
100.0\end{array}$ & $\begin{array}{l}21 \\
6 \\
1 \\
0 \\
0 \\
0 \\
1 \\
0 \\
0 \\
11 \\
0 \\
16 \\
13 \\
1 \\
26 \\
39 \\
10 \\
12 \\
5 \\
162\end{array}$ & $\begin{array}{r}13.0 \\
3.7 \\
0.6 \\
0.0 \\
0.0 \\
0.0 \\
0.6 \\
0.0 \\
0.0 \\
6.8 \\
0.0 \\
9.7 \\
8.0 \\
0.6 \\
16.0 \\
24.1 \\
6.2 \\
7.4 \\
3.1 \\
100.0\end{array}$ & $\begin{array}{l}44 \\
124 \\
0 \\
0 \\
1 \\
0 \\
0 \\
0 \\
0 \\
0 \\
0 \\
7 \\
7 \\
0 \\
17 \\
17 \\
1 \\
2 \\
2 \\
222\end{array}$ & $\begin{array}{r}19.8 \\
55.9 \\
0.0 \\
0.0 \\
0.5 \\
0.0 \\
0.0 \\
0.0 \\
0.0 \\
0.0 \\
0.0 \\
3.3 \\
3.2 \\
0.0 \\
7.7 \\
7.7 \\
0.5 \\
0.9 \\
0.9 \\
100.0\end{array}$ & $\begin{array}{l}36 \\
112 \\
8 \\
1 \\
0 \\
1 \\
2 \\
0 \\
0 \\
0 \\
1 \\
31 \\
21 \\
0 \\
22 \\
20 \\
8 \\
3 \\
9 \\
275\end{array}$ & $\begin{array}{r}13.1 \\
40.7 \\
2.9 \\
0.4 \\
0.0 \\
0.4 \\
0.7 \\
0.0 \\
0.0 \\
0.0 \\
0.4 \\
11.3 \\
7.6 \\
0.0 \\
8.0 \\
7.3 \\
2.9 \\
1.1 \\
3.3 \\
100.0\end{array}$ & $\begin{array}{l}54 \\
54 \\
5 \\
0 \\
0 \\
0 \\
2 \\
0 \\
0 \\
1 \\
3 \\
78 \\
28 \\
0 \\
48 \\
72 \\
26 \\
14 \\
16 \\
401\end{array}$ & $\begin{array}{r}13.5 \\
13.5 \\
1.2 \\
0.0 \\
0.0 \\
0.0 \\
0.5 \\
0.0 \\
0.0 \\
0.2 \\
0.7 \\
19.5 \\
7.0 \\
0.0 \\
12.0 \\
18.0 \\
6.5 \\
3.5 \\
4.0 \\
100.0\end{array}$ & $\begin{array}{l}47 \\
31 \\
2 \\
0 \\
1 \\
0 \\
0 \\
0 \\
0 \\
1 \\
2 \\
113 \\
15 \\
2 \\
43 \\
67 \\
29 \\
15 \\
9 \\
377\end{array}$ & $\begin{array}{r}12.5 \\
8.2 \\
0.5 \\
0.0 \\
0.3 \\
0.0 \\
0.0 \\
0.0 \\
0.0 \\
0.3 \\
0.5 \\
30.0 \\
4.0 \\
0.5 \\
11.4 \\
17.8 \\
7.7 \\
4.0 \\
2.4 \\
100.0\end{array}$ \\
\hline $\begin{array}{l}\text { Edad de los miembros: } \\
\text { Cinco años o menores } \\
\text { Cinco a doce años (12) } \\
\text { Mayores de doce años }(20) \\
\text { Total }\end{array}$ & $\begin{array}{l}176 \\
191 \\
541 \\
909\end{array}$ & $\begin{array}{r}19.4 \\
21.0 \\
59.6 \\
100.0\end{array}$ & $\begin{array}{l}168 \\
163 \\
520 \\
851\end{array}$ & $\begin{array}{r}19.7 \\
19.2 \\
61.1 \\
100.0\end{array}$ & $\begin{array}{l}175 \\
186 \\
564 \\
925\end{array}$ & $\begin{array}{r}18.9 \\
20.1 \\
61.0 \\
100.0\end{array}$ & $\begin{array}{l}320 \\
344 \\
873 \\
1537\end{array}$ & $\begin{array}{r}20.8 \\
22.4 \\
56.8 \\
.100 .0\end{array}$ & $\begin{array}{l}432 \\
535 \\
1382 \\
2349\end{array}$ & $\begin{array}{r}18.4 \\
22.8 \\
58.8 \\
100.0\end{array}$ & $\begin{array}{l}367 \\
487 \\
1558 \\
2412\end{array}$ & $\begin{array}{r}15.2 \\
20.2 \\
64.6 \\
100.0\end{array}$ \\
\hline $\begin{array}{l}\text { Posicion en la ocupacion: } \\
\text { Obrero o empleado } 11\} \\
\text { Patron (2) } \\
\text { Trabajador por cuenta propia (3) } \\
\text { Trabaja para la familia \$In remuneración (4) } \\
\text { No sabe o no responde (9) } \\
\text { Total }\end{array}$ & $\begin{array}{l}151 \\
8 \\
70 \\
21 \\
1 \\
251\end{array}$ & $\begin{array}{r}60.16 \\
3.19 \\
27.89 \\
8.37 \\
0.39 \\
100.00\end{array}$ & $\begin{array}{l}196 \\
8 \\
43 \\
20 \\
0 \\
267\end{array}$ & $\begin{array}{r}73.41 \\
3.0 \\
16.10 \\
7.49 \\
0.0 \\
100.00\end{array}$ & $\begin{array}{l}99 \\
6 \\
145 \\
59 \\
1 \\
310\end{array}$ & $\begin{array}{r}31.94 \\
1.94 \\
46.77 \\
19.03 \\
0.32 \\
100.00\end{array}$ & $\begin{array}{l}204 \\
4 \\
133 \\
39 \\
2 \\
382\end{array}$ & $\begin{array}{r}53.40 \\
1.05 \\
34.82 \\
10.21 \\
0.52 \\
100.00\end{array}$ & $\begin{array}{l}443 \\
11 \\
143 \\
26 \\
7 \\
630\end{array}$ & $\begin{array}{r}70.32 \\
1.75 \\
22.70 \\
4.13 \\
1.10 \\
100.00\end{array}$ & $\begin{array}{l}567 \\
10 \\
114 \\
16 \\
3 \\
710\end{array}$ & $\begin{array}{r}79.86 \\
1.41 \\
16.06 \\
2.25 \\
0.42 \\
100.00\end{array}$ \\
\hline
\end{tabular}


Cuadro 6

(continuacion)

\begin{tabular}{|c|c|c|c|c|c|c|c|c|c|c|c|c|}
\hline & \multicolumn{2}{|l|}{4.1} & \multicolumn{2}{|c|}{4.2} & \multicolumn{2}{|c|}{4.3} & \multicolumn{2}{|c|}{4.4} & \multicolumn{2}{|c|}{5.1} & \multicolumn{2}{|l|}{5.2} \\
\hline & Personas & 8 & Personas & 8 & Personas & 8 & Personas & $z$ & Personas & 8 & Personas & 8 \\
\hline $\begin{array}{l}\text { Edad promedio del jefe del hogar } \\
\text { Nive1 de instrucci6n del jefe del hogar: }\end{array}$ & 50.94 & & 42.71 & & 42.56 & & 45.90 & & 48.58 & & 44.57 & \\
\hline $\begin{array}{l}\text { Sin instruccion } \\
\text { Primaria incompleta } \\
\text { A1 menos primaria completa } \\
\text { No especificado } \\
\text { Total }\end{array}$ & $\begin{array}{l}178 \\
104 \\
10\end{array}$ & $\begin{array}{r}60.8 \\
35.5 \\
3.4 \\
0.3 \\
100.0\end{array}$ & $\begin{array}{l}155 \\
140 \\
41 \\
2 \\
338\end{array}$ & $\begin{array}{r}45.9 \\
41.4 \\
12.1 \\
0.6 \\
100.0\end{array}$ & $\begin{array}{l}88 \\
124 \\
67 \\
2 \\
281\end{array}$ & $\begin{array}{r}31.3 \\
44.1 \\
23.8 \\
0.7 \\
100.0\end{array}$ & $\begin{array}{l}35 \\
58 \\
93 \\
2 \\
138\end{array}$ & $\begin{array}{r}18.6 \\
30.9 \\
49.5 \\
100.1 \\
100.0\end{array}$ & $\begin{array}{l}295 \\
253 \\
35 \\
1 \\
584\end{array}$ & $\begin{array}{r}50.5 \\
43.3 \\
6.0 \\
0.2 \\
100.0\end{array}$ & $\begin{array}{l}145 \\
184 \\
63 \\
7 \\
399\end{array}$ & $\begin{array}{r}36.3 \\
46.1 \\
15.8 \\
1.8 \\
100.0\end{array}$ \\
\hline $\begin{array}{l}\text { Actividad del jefe del hogar: } \\
\text { Sin actividad } \\
\text { Agricultura } \\
\text { Ganadersa } \\
\text { Avicultura } \\
\text { Silvicultura } \\
\text { pesca } \\
\text { Combinacion Agropecuarla } \\
\text { Otras Acts. Agropecuarlas } \\
\text { Acts. Agropec-Insuficiente/especific. } \\
\text { Extrac. y refinacion de petroleo y gas } \\
\text { Extrac. de minas y canteras } \\
\text { Industrias de transformacion } \\
\text { Construcci6n } \\
\text { Electricidad } \\
\text { Comercio } \\
\text { Servicios } \\
\text { Transportes } \\
\text { Gobierno } \\
\text { No especificadas en las anteriores } \\
\text { rotal }\end{array}$ & $\begin{array}{l}48 \\
166 \\
8 \\
1 \\
1 \\
0 \\
2 \\
0 \\
1 \\
0 \\
1 \\
21 \\
5 \\
1 \\
15 \\
15 \\
5 \\
1\end{array}$ & $\begin{array}{r}16.4 \\
56.7 \\
2.7 \\
0.3 \\
0.3 \\
0.0 \\
0.7 \\
0.0 \\
0.3 \\
0.0 \\
0.3 \\
7.0 \\
1.7 \\
0.3 \\
5.1 \\
5.1 \\
1.7 \\
0.3 \\
0.7 \\
100.0\end{array}$ & $\begin{array}{l}30 \\
153 \\
14 \\
0 \\
0 \\
3 \\
0 \\
0 \\
1 \\
0 \\
2 \\
47 \\
25 \\
0 \\
21 \\
24 \\
9 \\
4 \\
5 \\
338\end{array}$ & $\begin{array}{r}8.9 \\
45.3 \\
4.1 \\
0.0 \\
0.0 \\
0.9 \\
0.0 \\
0.0 \\
0.3 \\
0.0 \\
0.6 \\
14.0 \\
7.4 \\
0.0 \\
6.2 \\
7.1 \\
2.7 \\
1.2 \\
1.5 \\
100.0\end{array}$ & $\begin{array}{l}22 \\
67 \\
7 \\
0 \\
0 \\
0 \\
0 \\
1 \\
1 \\
5 \\
1 \\
31 \\
39 \\
1 \\
32 \\
35 \\
24 \\
10 \\
5 \\
281\end{array}$ & $\begin{array}{r}7.8 \\
2.3 .8 \\
2.5 \\
0.0 \\
0.0 \\
0.0 \\
0.0 \\
0.4 \\
0.4 \\
1.8 \\
0.4 \\
11.2 \\
13.9 \\
0.4 \\
11.4 \\
12.5 \\
8.5 \\
3.6 \\
1.8 \\
100.0\end{array}$ & $\begin{array}{l}31 \\
10 \\
1 \\
29 \\
35 \\
17 \\
8 \\
6 \\
187\end{array}$ & $\begin{array}{r}13.3 \\
10.6 \\
2.1 \\
0.0 \\
0.0 \\
0.0 \\
0.0 \\
0.0 \\
0.0 \\
1.1 \\
16.5 \\
5.3 \\
0.5 \\
15.4 \\
18.6 \\
9.0 \\
4.3 \\
3.2 \\
100.0\end{array}$ & $\begin{array}{l}102 \\
349 \\
9 \\
1 \\
1 \\
0 \\
1 \\
0 \\
0 \\
0 \\
2 \\
28 \\
25 \\
0 \\
30 \\
29 \\
1 \\
2 \\
4 \\
584\end{array}$ & $\begin{array}{r}17.5 \\
59.8 \\
1.5 \\
0.2 \\
0.2 \\
0.0 \\
0.2 \\
0.0 \\
0.0 \\
0.0 \\
0.4 \\
4.9 \\
4.3 \\
0.0 \\
5.1 \\
5.0 \\
0.2 \\
0.3 \\
0.7 \\
100.0\end{array}$ & $\begin{array}{l}51 \\
166 \\
3 \\
0 \\
1 \\
0 \\
3 \\
1 \\
1 \\
0 \\
4 \\
37 \\
44 \\
0 \\
39 \\
34 \\
8 \\
4 \\
3 \\
399\end{array}$ & $\begin{array}{r}12.8 \\
41.5 \\
0.8 \\
0.0 \\
0.3 \\
0.0 \\
0.8 \\
0.3 \\
0.3 \\
0.0 \\
1.1 \\
9.7 \\
11.0 \\
0.0 \\
9.8 \\
8.5 \\
2.0 \\
1.0 \\
0.8 \\
100.0\end{array}$ \\
\hline $\begin{array}{l}\text { Total } \\
\text { Edad de los miembros } \\
\text { Cinco años o menores } \\
\text { Cinco a doce años } \\
\text { Mayores de } 12 \text { años } \\
\text { rotal }\end{array}$ & $\begin{array}{l}256 \\
270 \\
776 \\
1302\end{array}$ & $\begin{array}{r}19.7 \\
20.7 \\
59.6 \\
100.0\end{array}$ & $\begin{array}{l}434 \\
473 \\
1054 \\
1961\end{array}$ & $\begin{array}{r}22.1 \\
24.1 \\
53.7 \\
100.0\end{array}$ & $\begin{array}{l}376 \\
403 \\
1063 \\
1842\end{array}$ & $\begin{array}{r}20.4 \\
21.9 \\
57.7 \\
100.0\end{array}$ & $\begin{array}{l}207 \\
293 \\
849 \\
1349\end{array}$ & $\begin{array}{r}100.0 \\
15.3 \\
21.7 \\
62.9 \\
100.0\end{array}$ & $\begin{array}{l}564 \\
610 \\
1602 \\
2776\end{array}$ & $\begin{array}{r}100.0 \\
20.3 \\
22.0 \\
57.7 \\
100.0\end{array}$ & $\begin{array}{l}507 \\
567 \\
1377 \\
2451\end{array}$ & $\begin{array}{r}20.7 \\
23.1 \\
56.2 \\
100.0\end{array}$ \\
\hline $\begin{array}{l}\text { Posicion an la ocupacion: } \\
\text { Obrero o empleado } \\
\text { Patron } \\
\text { Trabajador por cuenta propia } \\
\text { Trabaja para la familia sin remuneracion } \\
\text { No sabe o no responde } \\
\text { Total }\end{array}$ & $\begin{array}{l}149 \\
1 \\
172 \\
62 \\
1 \\
385\end{array}$ & $\begin{array}{r}38.70 \\
0.26 \\
44.68 \\
16.10 \\
0.26 \\
100.00\end{array}$ & $\begin{array}{l}313 \\
4 \\
120 \\
57 \\
9 \\
503\end{array}$ & $\begin{array}{r}62.23 \\
0.80 \\
23.86 \\
11.33 \\
1.78 \\
100.00\end{array}$ & $\begin{array}{l}338 \\
9 \\
125 \\
42 \\
5 \\
519\end{array}$ & $\begin{array}{r}65.13 \\
1.73 \\
24.09 \\
8.09 \\
0.96 \\
100.00\end{array}$ & $\begin{array}{l}256 \\
19 \\
80 \\
60 \\
5 \\
420\end{array}$ & $\begin{array}{r}60.95 \\
4.52 \\
19.05 \\
14.29 \\
1.19 \\
100.00\end{array}$ & $\begin{array}{l}334 \\
7 \\
299 \\
141 \\
1 \\
782\end{array}$ & $\begin{array}{r}42.71 \\
0.90 \\
38.24 \\
18.03 \\
0.12 \\
100.00\end{array}$ & $\begin{array}{l}333 \\
4 \\
203 \\
113 \\
6 \\
659\end{array}$ & $\begin{array}{r}50.5 \\
0.6 \\
30.8 \\
17.1 \\
0.9 \\
100.0\end{array}$ \\
\hline
\end{tabular}




\begin{tabular}{|c|c|c|c|c|c|c|c|c|c|c|c|c|}
\hline & \multicolumn{2}{|c|}{5.3} & \multicolumn{2}{|c|}{5.4} & \multicolumn{2}{|l|}{6.1} & \multicolumn{2}{|l|}{6.2} & \multicolumn{2}{|c|}{6.3} & \multicolumn{2}{|l|}{6.4} \\
\hline & Personas & 8 & Personas & 8 & Personas & 8 & ersonas & 8 & Personas & 8 & Personas & 8 \\
\hline Edad promedio del jefe del hogar & 42.76 & & 44.42 & & 41.53 & & 41.55 & & 41.15 & & 43.89 & \\
\hline $\begin{array}{l}\text { Nivel de instruccion del jefe del hogar: } \\
\text { Sin instruccibn } \\
\text { Primarla incompleta } \\
\text { Al menos primaria completa } \\
\text { No especiflcado } \\
\text { Total }\end{array}$ & $\begin{array}{l}77 \\
149 \\
149 \\
2 \\
377\end{array}$ & $\begin{array}{r}20.4 \\
39.5 \\
39.5 \\
0.5 \\
100.0\end{array}$ & $\begin{array}{l}25 \\
39 \\
59 \\
0 \\
123\end{array}$ & $\begin{array}{r}20.3 \\
31.7 \\
48.0 \\
0.0 \\
100.0\end{array}$ & $\begin{array}{l}155 \\
104 \\
13 \\
2 \\
274\end{array}$ & $\begin{array}{r}56.6 \\
38.0 \\
4.7 \\
0.7 \\
100.0\end{array}$ & $\begin{array}{l}70 \\
98 \\
15 \\
2 \\
185\end{array}$ & $\begin{array}{r}37.8 \\
53.0 \\
8.1 \\
1.1 \\
100.0\end{array}$ & $\begin{array}{l}27 \\
46 \\
28 \\
0 \\
101\end{array}$ & $\begin{array}{r}26.7 \\
45.5 \\
27.7 \\
0.7 \\
100.0\end{array}$ & $\begin{array}{l}18 \\
21 \\
44 \\
1 \\
84\end{array}$ & $\begin{array}{r}21.4 \\
25.0 \\
52.4 \\
1.2 \\
100.0\end{array}$ \\
\hline $\begin{array}{l}\text { Actividad del jefe del hogar: } \\
\text { Sin Actividad } \\
\text { Agricultura } \\
\text { Ganaderla } \\
\text { Avicultura } \\
\text { Silvicultura } \\
\text { Pesca } \\
\text { Combinacion Agropecuaria } \\
\text { Otras Actividades Agropecuarias } \\
\text { Acts. Agropec. InsuficlentefEspecific. } \\
\text { Extrac. y refinacion de petrleo y gas } \\
\text { Extraccibn de minas y canteras } \\
\text { Industrias de transformac16n } \\
\text { Construccion } \\
\text { Electricidad } \\
\text { Comercio } \\
\text { Servicios } \\
\text { Transportes } \\
\text { Goblerno } \\
\text { No especificadas en las anteriores } \\
\text { Total }\end{array}$ & $\begin{array}{l}49 \\
64 \\
2 \\
1 \\
1 \\
0 \\
3 \\
0 \\
0 \\
1 \\
3 \\
89 \\
30 \\
1 \\
46 \\
48 \\
19 \\
16 \\
4 \\
377\end{array}$ & $\begin{array}{r}13.0 \\
17.0 \\
0.5 \\
0.3 \\
0.3 \\
0.0 \\
0.8 \\
0.0 \\
0.0 \\
0.3 \\
0.9 \\
23.7 \\
8.0 \\
0.3 \\
12.2 \\
12.7 \\
5.0 \\
4.2 \\
1.1 \\
100.0\end{array}$ & $\begin{array}{l}10 \\
14 \\
2 \\
0 \\
2 \\
0 \\
0 \\
0 \\
0 \\
0 \\
0 \\
35 \\
6 \\
3 \\
16 \\
25 \\
4 \\
6 \\
0 \\
123\end{array}$ & $\begin{array}{r}8.1 \\
11.4 \\
1.6 \\
0.1 \\
1.6 \\
0.0 \\
0.0 \\
0.0 \\
0.0 \\
0.0 \\
0.0 \\
28.4 \\
4.9 \\
2.4 \\
13.0 \\
20.3 \\
3.3 \\
4.9 \\
0.0 \\
100.0\end{array}$ & $\begin{array}{l}12 \\
226 \\
6 \\
1 \\
1 \\
0 \\
1 \\
0 \\
0 \\
0 \\
0 \\
8 \\
1 \\
0 \\
9 \\
5 \\
2 \\
0 \\
2 \\
274\end{array}$ & $\begin{array}{r}4.4 \\
82.5 \\
2.2 \\
0.4 \\
0.4 \\
0.0 \\
0.4 \\
0.0 \\
0.0 \\
0.0 \\
0.0 \\
3.0 \\
0.4 \\
0.0 \\
3.3 \\
1.8 \\
0.7 \\
0.0 \\
0.7 \\
100.0\end{array}$ & $\begin{array}{l}12 \\
113 \\
3 \\
0 \\
0 \\
0 \\
1 \\
0 \\
0 \\
2 \\
0 \\
11 \\
12 \\
0 \\
14 \\
11 \\
0 \\
5 \\
1 \\
185\end{array}$ & $\begin{array}{r}6.5 \\
61.1 \\
1.6 \\
0.0 \\
0.0 \\
0.0 \\
0.5 \\
0.0 \\
0.0 \\
1.1 \\
0.0 \\
5.9 \\
6.5 \\
0.0 \\
7.6 \\
5.9 \\
0.0 \\
2.7 \\
0.5 \\
100.0\end{array}$ & $\begin{array}{l}7 \\
24 \\
0 \\
0 \\
0 \\
0 \\
0 \\
0 \\
0 \\
5 \\
0 \\
17 \\
7 \\
0 \\
12 \\
13 \\
5 \\
7 \\
4 \\
101\end{array}$ & $\begin{array}{r}6.9 \\
23.8 \\
0.0 \\
0.0 \\
0.0 \\
0.0 \\
0.0 \\
0.0 \\
0.0 \\
5.0 \\
0.0 \\
17.0 \\
6.9 \\
0.0 \\
11.9 \\
12.9 \\
5.0 \\
6.9 \\
4.0 \\
100.0\end{array}$ & $\begin{array}{l}7 \\
12 \\
1 \\
1 \\
1 \\
1 \\
0 \\
0 \\
0 \\
10 \\
2 \\
12 \\
7 \\
0 \\
8 \\
12 \\
4 \\
3 \\
3 \\
84\end{array}$ & $\begin{array}{r}8.3 \\
14.3 \\
1.2 \\
1.2 \\
1.2 \\
1.2 \\
0.0 \\
0.0 \\
0.0 \\
11.9 \\
2.4 \\
14.4 \\
8.3 \\
0.0 \\
9.5 \\
14.3 \\
4.8 \\
3.6 \\
3.6 \\
100.0\end{array}$ \\
\hline $\begin{array}{l}\text { Edad de } 105 \text { miembros } \\
\text { Cínco años o menores } \\
\text { Cinco a doce años } \\
\text { Mayores de doce años } \\
\text { Total }\end{array}$ & $\begin{array}{l}475 \\
534 \\
1366 \\
2376\end{array}$ & $\begin{array}{r}20.0 \\
22.5 \\
57.5 \\
100.0\end{array}$ & $\begin{array}{l}188 \\
578 \\
766\end{array}$ & $\begin{array}{r}24.5 \\
73.5 \\
100.0\end{array}$ & & $\begin{array}{r}20.3 \\
21.7 \\
58.0 \\
100.0\end{array}$ & $\begin{array}{l}212 \\
959 \\
608 \\
1779\end{array}$ & $\begin{array}{r}11.9 \\
53.9 \\
34.2 \\
100.0\end{array}$ & $\begin{array}{l}107 \\
153 \\
333 \\
593\end{array}$ & $\begin{array}{r}18.0 \\
25.8 \\
56.2 \\
100.0\end{array}$ & $\begin{array}{l}76 \\
77 \\
326 \\
479\end{array}$ & $\begin{array}{r}15.9 \\
16.1 \\
68.1 \\
100.0\end{array}$ \\
\hline $\begin{array}{l}\text { Pos1c16n en la ocupac16n } \\
\text { Obrero o empleado } \\
\text { patr6n } \\
\text { Trabajador por cuenta propia } \\
\text { Trabaja para la familla sin remunerac } 16 \mathrm{n} \\
\text { No sabe o no responde } \\
\text { Total }\end{array}$ & $\begin{array}{l}421 \\
9 \\
140 \\
69 \\
4 \\
643\end{array}$ & $\begin{array}{r}65.47 \\
1.40 \\
21.77 \\
10.73 \\
0.63 \\
100.00\end{array}$ & $\begin{array}{l}174 \\
10 \\
57 \\
34 \\
1 \\
276\end{array}$ & $\begin{array}{r}63.04 \\
3.62 \\
20.65 \\
12.32 \\
0.34 \\
100.00\end{array}$ & $\begin{array}{l}168 \\
8 \\
152 \\
61 \\
0 \\
389\end{array}$ & $\begin{array}{r}43.19 \\
2.06 \\
39.08 \\
15.67 \\
0.0 \\
100.00\end{array}$ & $\begin{array}{l}179 \\
4 \\
87 \\
27 \\
0 \\
297\end{array}$ & $\begin{array}{r}60.27 \\
1.35 \\
29.29 \\
9.09 \\
0.0 \\
100.00\end{array}$ & $\begin{array}{l}121 \\
1 \\
37 \\
8 \\
4 \\
171\end{array}$ & $\begin{array}{r}70.76 \\
0.59 \\
21.64 \\
4.68 \\
2.33 \\
100.00\end{array}$ & $\begin{array}{l}116 \\
2 \\
32 \\
4 \\
6 \\
160\end{array}$ & $\begin{array}{r}72.5 \\
1.3 \\
20.0 \\
2.5 \\
3.8 \\
100.0\end{array}$ \\
\hline
\end{tabular}


Cuadro 6

(continuacion)

\begin{tabular}{|c|c|c|c|c|c|c|c|c|c|c|c|c|}
\hline & \multicolumn{2}{|c|}{7.1} & \multicolumn{2}{|c|}{7.2} & \multicolumn{2}{|c|}{7.3} & \multicolumn{2}{|l|}{7.4} & \multicolumn{2}{|l|}{8.1} & \multicolumn{2}{|l|}{8.2} \\
\hline & Personas & 8 & Personas & 8 & Personas & 8 & Personas & 8 & Personas & 8 & Persones & 8 \\
\hline Edad promedio del jefe del hogar & 46.84 & & 44.49 & & 40.71 & & 43.15 & & 48.59 & & 41.53 & \\
\hline $\begin{array}{l}\text { Nivel de instruccion del jefe del hogar } \\
\text { Sivi Instruccibn } \\
\text { Primaria incompleta } \\
\text { Al menos primaria completa } \\
\text { No especificado } \\
\text { Total }\end{array}$ & $\begin{array}{l}70 \\
92 \\
7 \\
2 \\
171\end{array}$ & $\begin{array}{r}40.9 \\
53.8 \\
4.1 \\
1.2 \\
100.0\end{array}$ & $\begin{array}{l}37 \\
124 \\
21 \\
1 \\
183\end{array}$ & $\begin{array}{r}20.2 \\
67.8 \\
11.5 \\
0.5 \\
100.0\end{array}$ & $\begin{array}{l}25 \\
128 \\
63 \\
2 \\
218\end{array}$ & $\begin{array}{r}11.5 \\
58.7 \\
28.9 \\
0.9 \\
100.0\end{array}$ & $\begin{array}{l}8 \\
49 \\
121 \\
1 \\
179\end{array}$ & $\begin{array}{r}4.5 \\
27.4 \\
67.6 \\
0.6 \\
100.0\end{array}$ & $\begin{array}{l}152 \\
119 \\
5 \\
5 \\
281\end{array}$ & $\begin{array}{r}54.1 \\
42.3 \\
1.8 \\
1.8 \\
100.0\end{array}$ & $\begin{array}{l}118 \\
178 \\
30 \\
6 \\
332\end{array}$ & $\begin{array}{r}35.6 \\
53.8 \\
9.1 \\
2.2 \\
100.0\end{array}$ \\
\hline $\begin{array}{l}\text { Actividad del jefe del hogar } \\
\text { SIn actividad } \\
\text { Agricultura } \\
\text { Ganaderia } \\
\text { Avicultura } \\
\text { Silvicultura } \\
\text { Pesca } \\
\text { Combinacion Agropecuaria } \\
\text { Otras actividades agropecuarias } \\
\text { Acts. Agrope. Insuficiente Especific. } \\
\text { Extrac. yefinacion de petroleo y gas } \\
\text { Extraction de minas y canteras } \\
\text { Industrias de transformacion } \\
\text { Construccion } \\
\text { Electricidad } \\
\text { Comercio } \\
\text { Servicios } \\
\text { Transportes } \\
\text { Gobierno } \\
\text { No especificadas en las anteriores } \\
\text { Total }\end{array}$ & $\begin{array}{l}18 \\
118 \\
6 \\
0 \\
4 \\
0 \\
0 \\
0 \\
0 \\
0 \\
4 \\
4 \\
1 \\
0 \\
7 \\
7 \\
0 \\
0 \\
2 \\
171\end{array}$ & $\begin{array}{r}10.5 \\
69.0 \\
3.5 \\
0.0 \\
2.4 \\
0.0 \\
0.0 \\
0.0 \\
0.0 \\
0.0 \\
2.3 \\
2.4 \\
0.6 \\
0.0 \\
4.1 \\
4.1 \\
0.0 \\
0.0 \\
1.2 \\
100.0\end{array}$ & $\begin{array}{l}8 \\
86 \\
6 \\
0 \\
6 \\
0 \\
1 \\
0 \\
0 \\
0 \\
3 \\
22 \\
14 \\
0 \\
15 \\
14 \\
0 \\
3 \\
5 \\
183\end{array}$ & $\begin{array}{r}4.4 \\
47.2 \\
3.3 \\
0.0 \\
3.3 \\
0.0 \\
0.5 \\
0.0 \\
0.0 \\
0.0 \\
1.6 \\
11.8 \\
7.7 \\
0.0 \\
8.2 \\
7.7 \\
0.0 \\
1.6 \\
2.7 \\
100.0\end{array}$ & $\begin{array}{l}20 \\
28 \\
3 \\
2 \\
0 \\
1 \\
0 \\
0 \\
0 \\
0 \\
2 \\
32 \\
39 \\
1 \\
25 \\
32 \\
14 \\
15 \\
4 \\
218\end{array}$ & $\begin{array}{r}9.2 \\
12.8 \\
1.4 \\
0.9 \\
0.0 \\
0.5 \\
0.0 \\
0.0 \\
0.0 \\
0.0 \\
0.9 \\
14.9 \\
17.9 \\
0.5 \\
11.5 \\
14.7 \\
6.4 \\
6.9 \\
1.8 \\
100.0\end{array}$ & $\begin{array}{l}21 \\
6 \\
0 \\
0 \\
0 \\
0 \\
0 \\
1 \\
1 \\
0 \\
0 \\
23 \\
8 \\
5 \\
25 \\
53 \\
10 \\
23 \\
3 \\
179\end{array}$ & $\begin{array}{r}11.7 \\
3.4 \\
0.0 \\
0.0 \\
0.0 \\
0.0 \\
0.0 \\
0.6 \\
0.6 \\
0.0 \\
0.0 \\
12.9 \\
4.5 \\
2.8 \\
14.0 \\
29.6 \\
5.6 \\
12.8 \\
11.7 \\
100.0\end{array}$ & $\begin{array}{l}24 \\
205 \\
4 \\
1 \\
2 \\
0 \\
0 \\
0 \\
0 \\
0 \\
0 \\
5 \\
5 \\
0 \\
15 \\
17 \\
1 \\
0 \\
2 \\
281\end{array}$ & $\begin{array}{r}8.5 \\
73.0 \\
1.4 \\
0.4 \\
0.7 \\
0.0 \\
0.0 \\
0.0 \\
0.0 \\
0.0 \\
0.0 \\
1.9 \\
1.8 \\
0.0 \\
5.3 \\
6.0 \\
0.4 \\
0.0 \\
0.7 \\
100.0\end{array}$ & $\begin{array}{l}19 \\
182 \\
7 \\
0 \\
0 \\
10 \\
0 \\
0 \\
1 \\
0 \\
1 \\
27 \\
28 \\
2 \\
18 \\
20 \\
5 \\
3 \\
9 \\
332\end{array}$ & $\begin{array}{r}5.7 \\
54.8 \\
2.1 \\
0.0 \\
0.0 \\
3.0 \\
0.0 \\
0.0 \\
0.3 \\
0.0 \\
0.3 \\
8.1 \\
8.4 \\
0.6 \\
5.4 \\
6.0 \\
1.5 \\
0.9 \\
2.7 \\
100.0\end{array}$ \\
\hline $\begin{array}{l}\text { Edad: de los miembros } \\
\text { Cínco años o menores } \\
\text { Cinco a doce años } \\
\text { Mayores de doce años } \\
\text { Total }\end{array}$ & $\begin{array}{l}147 \\
141 \\
816 \\
704\end{array}$ & $\begin{array}{c}20.9 \\
20.10 \\
59: 1 \\
100.0\end{array}$ & $\begin{array}{l}195 \\
186 \\
622 \\
1003\end{array}$ & $\begin{array}{r}19.5 \\
18.5 \\
62.0 \\
100.0\end{array}$ & $\begin{array}{l}253 \\
249 \\
695 \\
1197\end{array}$ & $\begin{array}{r}21.1 \\
20.8 \\
58.1 \\
100.0\end{array}$ & $\begin{array}{l}175 \\
174 \\
688 \\
1037\end{array}$ & $\begin{array}{r}16.9 \\
16.8 \\
66.3 \\
100.0\end{array}$ & $\begin{array}{l}254 \\
322 \\
770 \\
1346\end{array}$ & $\begin{array}{r}18.9 \\
23.9 \\
57.2 \\
100.0\end{array}$ & $\begin{array}{l}396 \\
402 \\
1015 \\
1813\end{array}$ & $\begin{array}{r}21.8 \\
22.2 \\
56.0 \\
100.0\end{array}$ \\
\hline $\begin{array}{l}\text { Posicion en la ocupacion } \\
\text { Obrero o empleado } \\
\text { Patron } \\
\text { Trabajador por cuenta propia } \\
\text { Trabaja para la familia sin remuneracion } \\
\text { No sabe o no responde } \\
\text { Total }\end{array}$ & $\begin{array}{l}114 \\
0 \\
104 \\
12 \\
0 \\
230\end{array}$ & $\begin{array}{r}49.57 \\
0.00 \\
45.22 \\
5.21 \\
0.00 \\
100.00\end{array}$ & $\begin{array}{l}200 \\
4 \\
107 \\
34 \\
2 \\
347\end{array}$ & $\begin{array}{r}57.64 \\
1.15 \\
30.84 \\
9.80 \\
0.57 \\
100.00\end{array}$ & $\begin{array}{l}255 \\
2 \\
83 \\
7 \\
0 \\
347\end{array}$ & $\begin{array}{r}73.49 \\
0.58 \\
23.92 \\
2.01 \\
0.00 \\
100.00\end{array}$ & $\begin{array}{l}250 \\
5 \\
60 \\
4 \\
1 \\
320\end{array}$ & $\begin{array}{r}78.13 \\
1.56 \\
18.75 \\
1.25 \\
0.31 \\
100.00\end{array}$ & $\begin{array}{l}108 \\
0 \\
218 \\
94 \\
6 \\
426 \\
\end{array}$ & $\begin{array}{r}25.35 \\
0.00 \\
51.17 \\
22.07 \\
1.41 \\
100.00\end{array}$ & $\begin{array}{l}211 \\
9 \\
209 \\
88 \\
6 \\
523\end{array}$ & $\begin{array}{r}40.3 \\
1.7 \\
39.9 \\
16.8 \\
1.2 \\
100.0\end{array}$ \\
\hline
\end{tabular}




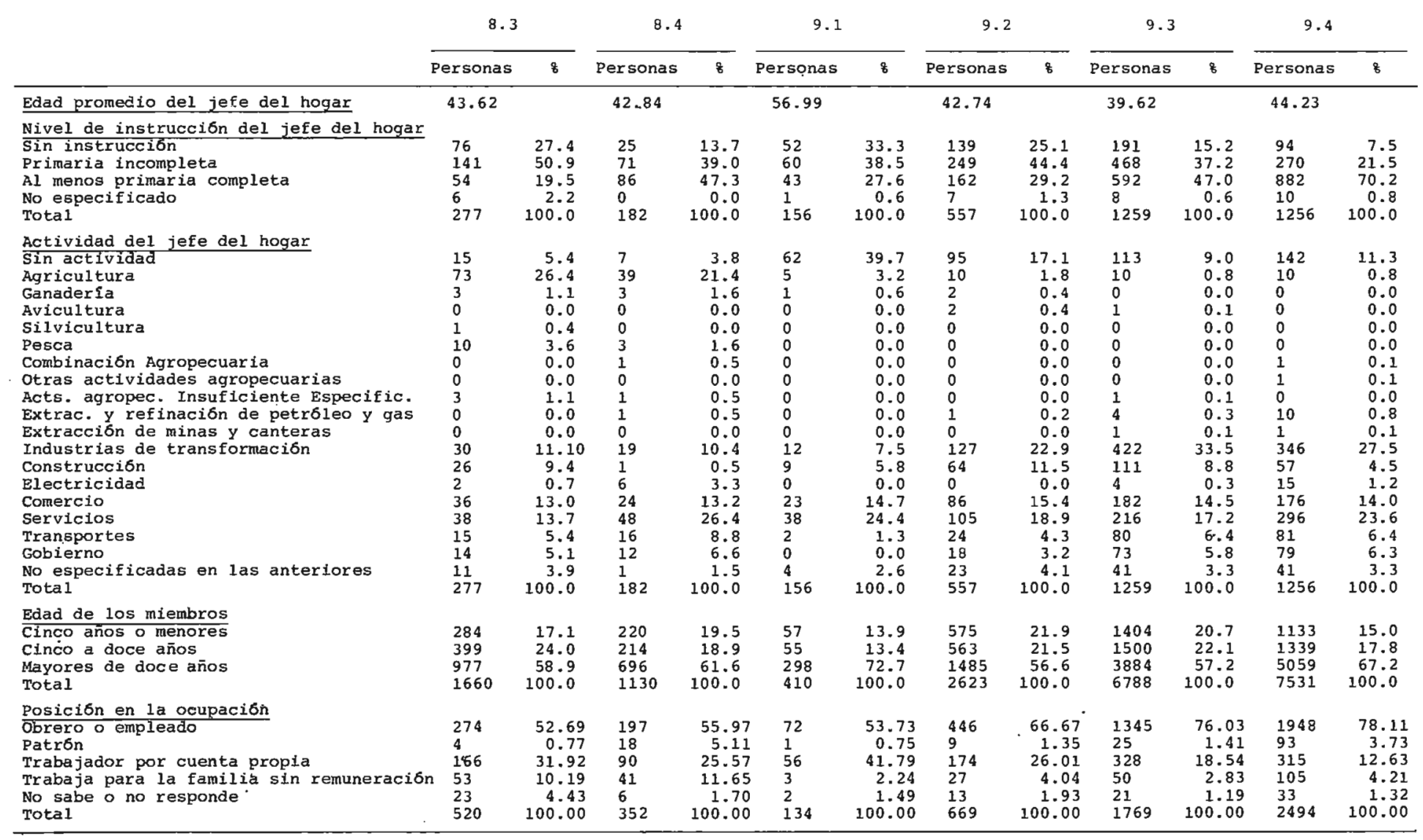

Fuente: Secretaría de Programación y Presupuesto, Coordinación General del Sistema Nacional de Informacion, "Encuesta Nacional de Lu gresos y Gastos de los Hogares 1977".

Nota: E1 primer digito de los numeros que encabezan las columnas se refiere a la regín (nueve regiones en total); y, el segun al estrato de ingreso: 1 , entre o y hasta medio
hasta dós; y. 4, más de dos salarios minimos. 
ción, el $47 \%$ tenía la primaria incompleta y sólo el $12 \%$ habra por lo menos completado la primaria; en el grupo de más de un salario mínimo los porcentajes análogos son: $13 \%, 41 \%$, y $45 \%$, respectivamente. En el grupo objetivo, $48 \%$ de los jefes se dedican a la agricultura, $8.7 \%$ a las industrias de transformación y $18 \%$ a los servicios; en contraste, en el otro grupo, sólo $9 \%$ de los jefes son agrícolas, un $22 \%$ trabaja en las industrias, y $46 \%$ está en el ramo de los servicios.

La carga de dependencia del grupo objetivo es mayor ya que el porcentaje de miembros menores de doce años es igual a $44 \%$, mientras que en el resto de la población es de $37.5 \%$. La importancia de este resultado reside en que, además de reflejar que en el grupo objetivo existe un menor número de personas susceptibles de ser ocupadas y contribuir al ingreso del hogar, indica que en la población con problemas de desnutrición existe un elevado número de niños menores de 12 años (alrededor de 9 millones) y de niños menores de 5 años (cerca de cuatro millones y medio):

En cuanto a la posición en la ocupación, el grupo por debajo del salario mínimo tiene una frecuencia relativamente alta de trabajadores por cuenta propia y sin remuneración $-36 \%$ y $13 \%$ respectivamente- y de asalariados igual al $49 \%$ cuando para el resto de los hogares los porcentajes correspondientes son $18 \%, 6 \%$ y $71.6 \%$.

La posición de los miembros en la ocupación, indica que la población más pobre del país está constituida principalmente por campesinos (pequeños propietarios y ejidatarios) que usan mano de obra familiar, por jornaleros agrícolas y por personas que trabajan en e1 llamado sector informal de las zonas urbanas (actividades contenidas en las ramas de servicios).

A nivel regional (excepto para las áreas metropolitanas (región 9), ${ }^{11}$ se puede observar una correlación muy clara entre grupo de ingreso, actividad del jefe y posición en la ocupación: a medida que se pasa de un grupo de ingreso a otro, la agricultura -que es la actividad predominante (y prácticamente única) entre los hogares más pobres (los que ganan hasta medio salario mínimo) - va perdiendo participación mientras que las actividades industriales y de servicios la incrementan; asimismo, el porcentaje de trabajadores por su cuenta (más alto que el de obreros o empleados en muchas de las regiones para el grupo de ingreso más bajo) y los que no reciben remuneración, disminuye a medida que el ingreso aumenta, mientras que la participación de asalariados y patrones va en aumento. Es interesante notar que, para los mismos grupos de ingreso, no se observan diferencias

11 En el caso de las áreas metropolitanás las actividades predominantes del grupo de ingresos más bajos son los servicios. 
importantes en la estructura de la actividad del jefe y de la posición en la ocupación, cuando se hace la comparación entre regiones. Hay una cierta tendencia, sin embargo, a que el grado de analfabetismo y la carga de dependencia sea mayor en el grupo más pobre de las regiones más pobres (regiones $4,5,6$ y 8 ).

En síntesis, se puede decir que la población con un nivel de pobreza mayor está compuesta, principalmente, por campesinos, que muchos de ellos explotan mano de obra familiar y venden la fuerza de trabajo de sus miembros, en el sector rural y en las áreas urbanas y metropolitanas; por pequeños comerciantes y personas que realizan un sinnumero de servicios (cuidacoches, lavacoches, barrenderos, porteros, servicio doméstico, etc.). También se ha visto que una alta proporción de la población más pobre tiene un alto porcentaje de niños menores de doce años. Esto significa que los problemas de desnutrición están afectando en un grado relativamente mayor a la población más joven del país.

\section{Estructura del consumo nacional y regional}

En el Cuadro 7 se ha calculado la distribución del gasto total en seis agregados de bienes para la población que gana hasta un salario mínimo, y para el resto de los hogares. Los seis agregados son: alimentos y bebidas; ${ }^{12}$ vestimenta y calzado; vivienda; educación; salud; transporte y comunicaciones; y otros gastos.

Como era previsible el grupo de hasta un salario minimo destinó una proporción mucho mayor al consumo de alimentos y bebidas $(55.7 \%)$, y bastante menor al de transporte y comunicaciones $(3.3 \%)$, que el resto de los hogares $(36.2 \%$ y $10.7 \%$, respectivamente). La diferencia, en el caso de alimentos, es reflejo de los bajos niveles de ingreso; $y$ en el de transportes y comunicaciones puede atribuirse a que el grupo más pobre prácticamente no consume automóviles. En los otros rubros, la diferencia es mucho menor.

Por otra parte, la porción de gasto en salud es relativamente más alta para este grupo (3.97\%), que para los hogares por encima del salario mínimo $(3.2 \%)$. O sea que, si bien en términos absolutos este último gasta más en salud, la carga relativa de este tipo de gasto es superior para el grupo más pobre.

Cuando se analiza la distribución del gasto en productos alimenti-

12 Incluye autoconsumo y no incluye alimentos consumidos fuera. El detalle de los bienes incluidos en cada uno de los agregados viene en el cuadro 38. 
Cujalin? 7

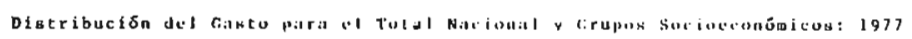

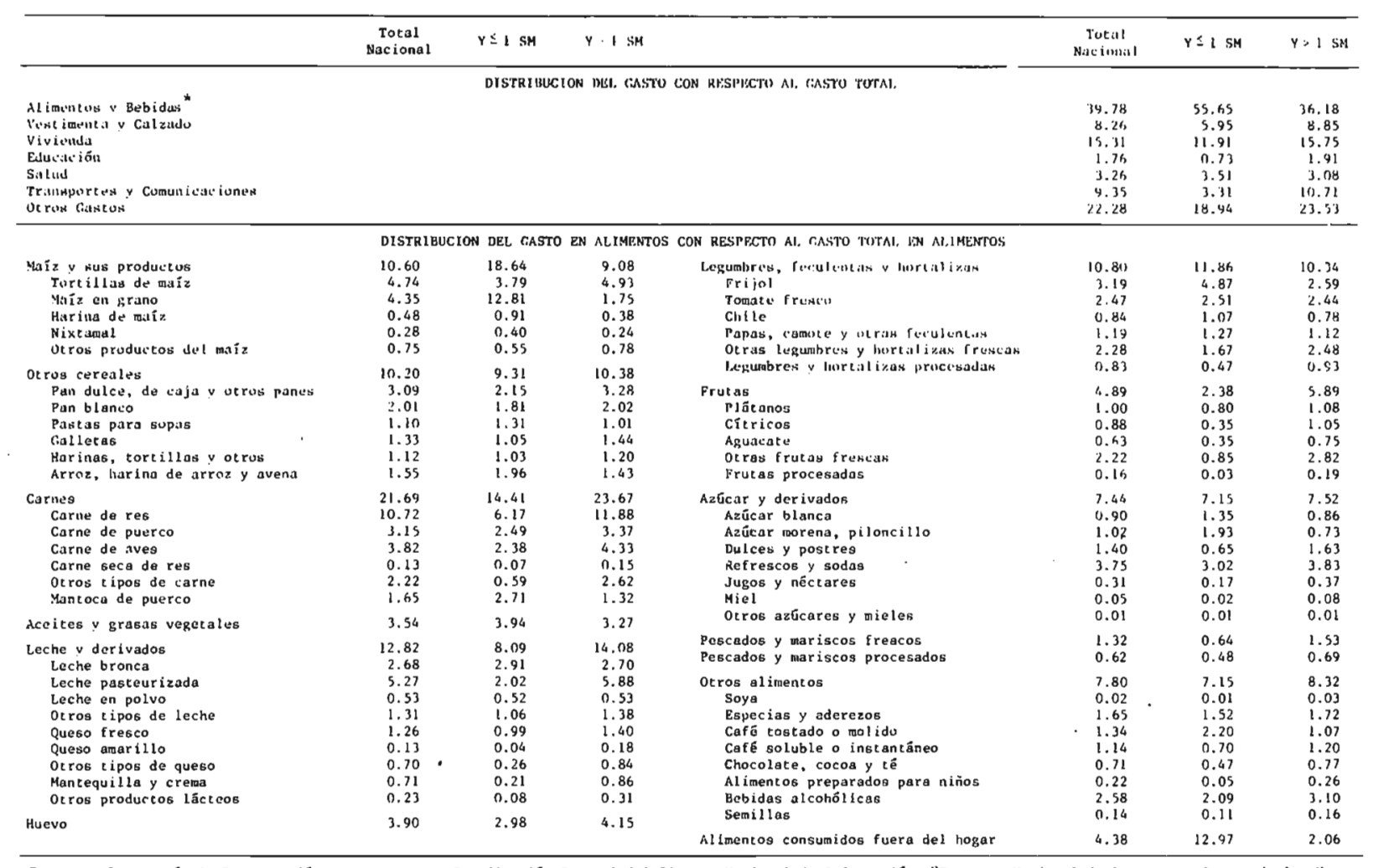
Sacretaría de Programación y presupuesto, Coordinación Ceneral del Sístema Nacional de Información, "Encuesta Nacional de Ingresos y Castos de los Ho- Incluye autoconsumo y no incluye alimentos consunidos fuera del hogar. 
cios en relación al gasto total en alimentos, ${ }^{13}$ se encuentra que los hogares de hasta un salario mfnimo destinan $18.6 \%$ del gasto total en alimentos a maíz y sus productos; $9.3 \%$ a otros cereales; $14.4 \%$ a carnes y derivados; $3 \%$ a huevos; $11.9 \%$ a legumbres y hortalizas frescas y procesadas; $2.4 \%$ a frutas frescas y procesadas; $7.2 \%$ a azúcar y derivados; $7.2 \%$ a otros alimentos y $2.5 \%$ a alimentos consumidos fuera del hogar. Los productos específicos que absorben una mayor proporción del gasto en alimentos son: maíz en grano $12.3 \%$; carne de res $6.2 \%$; frijol $4.9 \%$; aceites y grasas vegetales $4 \%$; tortillas de maiz $4 \%$; refrescos y sodas $3 \%$; huevos $3 \%$; leche bronca $2.9 \%$; manteca de puerco $2.7 \%$; tomate $2.5 \%$ y carne de puerco $2.5 \%$; estos once productos constituyen el $48 \%$ del gasto en alimentos. La proporción gastada por este grupo en café molido o tostado es de $2.2 \%$, en bebidas alcohólicas es igual a $2.1 \%$ y en pescados y mariscos frescos, es $0.6 \%$. La proporción de autoconsumo es casi el $13 \%$ del total gastado en alimentos (véase Cuadro 7).

En comparación con el grupo de hasta un salario mínimo, el resto de la población (los hogares que percibieron más de un salario mínimo) consume relativamente ( $\mathrm{y}$, por lo tanto, también en términos absolutos) mucho más, productos de origen animal por ejemplo; el gasto en carnes y derivados como proporción del gasto total en alimentos es del $23.7 \%$ y de $14.1 \%$ en leche y derivados; mientras que el porcentaje consumido en maíz y sus productos es sólo de $8.1 \%$ (menos de la mitad de la proporción análoga para el grupo objetivo). Los productos que representan alrededor del $50 \%$ del gasto en alimentos para el grupo de mayores ingresos, según orden de importancia, son: carne de res $11.9 \%$; leche pasteurizada $5.9 \%$; tortillas de mafz $4.9 \%$; carne de aves $4.3 \%$; huevo $4.2 \%$; refrescos y sodas $3.8 \%$; carne de puerco $3.4 \%$; pan dulce, de caja y otros panes $3.3 \%$; aceites y grasas vegetales $3.3 \%$; bebidas alcohólicas $3.1 \%$; otras frutas frescas $2.8 \%$.

Como era de esperarse, el autoconsumo de este grupo es pequeño: $2.1 \%$ del gasto en alimentos, la participación del gasto en pescados y mariscos frescos del total gastado en alimentos es $1.5 \%$.

A nivel regional, se observa en el Cuadro 8 que en las regiones más pobres $(4,5$ y 8 ), el estrato de hasta un salario mínimo (para los

\footnotetext{
13 E1 lector notará que la suma de los rubros parciales no coincide con el porcentaje gastado en alimentos y bebidas que presentamos anteriormente; esta paradoja ocurre en todos los casos porque la información en la encuesta se presenta así, y se debe a que los montos de cada uno se calcularon por vía de preguntas diferentes: una referida al total de alimentos y otras a los productos específicos; según se nos informó, cuando la discrepancia excedía un $10 \%$, el cuestionario era eliminado.
} 
Cuadro 8

Distribución del gasto en alimentos con respecto al cotal gastado on alimentos por grupo y raglon: 1977

\begin{tabular}{|c|c|c|c|c|c|c|c|c|c|c|c|c|c|c|}
\hline & 1.1 & 1.2 & 1.3 & 2.1 & 2.2 & 2.3 & 3.1 & 3.2 & 3.3 & 4.1 & 4.2 & 4.3 & 5.1 & 5.2 \\
\hline Maíz y вus productos & 11.86 & 9.53 & 6.59 & 10.84 & 12.15 & 7.78 & 15.46 & 17.09 & 9.83 & 21.19 & 19.32 & 11.50 & 2.25 & 23.07 \\
\hline Otros cereales & 11.54 & 15.19 & 9.88 & 11.56 & 11.49 & 8.91 & 10.46 & 10.62 & 8.46 & 9.13 & 11.64 & 10.75 & 10.82 & 9.91 \\
\hline Carne & 15.73 & 17.54 & 23.95 & 9.23 & 14.53 & 21.69 & 11.24 & 13.82 & 16.59 & 14.39 & 16.76 & 21.84 & 16.07 & 15.43 \\
\hline Leche y derivados & 10.99 & 14.26 & 14.85 & 3.54 & 11.82 & 13.45 & 6.45 & 12.59 & 10.72 & 9.11 & 14.60 & 16.93 & 4.55 & 7.48 \\
\hline Frutas & 1.74 & 2.25 & 4.80 & 2.16 & 2.04 & 5.24 & 1.50 & 2.51 & 3.70 & 2.44 & 2.74 & 4.77 & 2.73 & 2.86 \\
\hline Legumbres, feculentas y hortalizas & 12.12 & 11.17 & 9.89 & 11.93 & 11.05 & 10.65 & 11.08 & 12.65 & 7.96 & 15.76 & 14.19 & 12.00 & 18.45 & 14.14 \\
\hline Azúcar y derivados & 8.16 & 8.75 & 8.09 & 7.75 & 10.08 & 10.06 & 9.88 & 9.06 & 6.75 & 6.51 & 7.65 & 7.68 & 6.63 & 5.48 \\
\hline otros alimentos & 8.61 & 9.07 & 9.28 & 12.02 & 7.99 & 9.45 & 5.75 & 7.05 & 6.07 & 3.83 & 4.35 & 5.30 & 8.46 & 5.78 \\
\hline Aceites y grasas vegotales & 7.21 & 4.91 & 3.85 & 8.12 & 7.25 & 5.12 & 6.95 & 5.80 & 23.71 & 0.93 & 1.44 & 1.45 & 3.88 & 3.96 \\
\hline Huevo & 4.49 & 4.94 & 4.54 & 1.25 & 4.76 & 3.77 & 2.85 & 4.98 & 3.84 & 1.66 & 3.16 & 3.23 & 2.77 & 3.11 \\
\hline Pescados y mariscos frescos & 0.12 & 0.36 & 1.54 & 1.33 & 0.00 & 0.74 & 0.10 & 0.13 & 0.56 & 0.04 & 0.41 & 0.85 & 0.06 & 0.23 \\
\hline Pescados y mariscos procesados & 0.71 & 0.28 & 0.85 & 0.36 & 0.10 & 0.78 & 0.74 & 0.97 & 0.56 & 0.02 & 0.25 & 0.30 & 0.56 & 0.28 \\
\hline Autoconsumo & 6.69 & 1.75 & 1.89 & 19.91 & 6.74 & 2.36 & 17.64 & 2.73 & 1.25 & 14.81 & .3 .59 & 3.41 & 22.78 & 8.29 \\
\hline Total & 100,00 & 100.00 & 100.00 & 100.00 & 100.00 & 100.00 & 100,00 & 100.00 & 100.00 & 100.00 & 100.00 & 100.00 & 100.00 & 100.00 \\
\hline & & 5.3 & 6.1 & 6.2 & 6.3 & 7.1 & 7.2 & 7.3 & 8.1 & 8.2 & 8.3 & 9.1 & 9.2 & 9.3 \\
\hline Maiz y sus productos & & 10.52 & 21.64 & 21.34 & 8.66 & 23.48 & 15.05 & 6.72 & 16.58 & 20.32 & 2.57 & 9.87 & 9.64 & 6.28 \\
\hline Otros cereales & & 11.09 & 6.19 & 9.24 & 8.67 & 10.16 & 10.55 & 10.06 & 7.98 & 11.36 & 9.61 & 8.08 & 8.42 & 9.74 \\
\hline Carne & & 22.88 & 11.58 & 17.69 & 22.90 & 21.43 & 24.92 & 30.37 & 11.56 & 1.93 & 23.34 & 44.33 & 15.39 & 24,60 \\
\hline Leche y derivados & & 11.88 & 2.56 & 7.66 & 9.86 & 4.69 & 5.05 & $11 . \infty 0$ & 5.42 & 10.84 & 12.95 & 7.89 & 12.17 & 15.27 \\
\hline Frutas & & 5.66 & 0.74 & 2.51 & 5.73 & 1.94 & 3.69 & 5.96 & 2.07 & 3.34 & 5.18 & 1.77 & 3.32 & 6.52 \\
\hline Legumbres, feculentas y hortalizas & & 11.90 & 10.13 & 9.71 & 8.82 & 10.52 & 14.57 & 9.23 & 12.04 & 13.02 & 10.92 & 9.27 & 9.93 & 16.42 \\
\hline Azücar y derivados & & 6.71 & 6.46 & 6.33 & 8.44 & 8.00 & 8.62 & 7.65 & 6.88 & 8.88 & 8.03 & 6.28 & 5.47 & 6.79 \\
\hline Oeros alimentos & & 6.95 & 9.36 & 6.82 & 11.01 & 6.73 & 7.29 & 9.05 & 9.06 & 9.60 & 11.98 & 5.41 & 27.19 & 7.41 \\
\hline Aceites y grasas vegetales & & 2.92 & 4.29 & 4.63 & 3.89 & 1.18 & 2.18 & 2.60 & 4.24 & 4.20 & 3.19 & 1.75 & 3.09 & 0.40 \\
\hline Huevo & & 4.37 & 1.34 & 2.85 & 4.01 & 2.97 & 5.48 & 4.10 & 2.00 & 4.62 . & 3.85 & 2.69 & 3.69 & 3.97 \\
\hline Pescados y mariscos frescos & & 1.31 & 1.10 & 1.43 & 3.79 & 0.44 & 0.83 & 2.05 & 1.75 & 2.96 & 3.22 & 0.25 & 0.73 & 1.54 \\
\hline Pescados y maríscos procesados & & $0 . \dot{70}$ & 0.99 & 0.68 & 0.82 & 0.09 & 0.07 & 0.47 & 0.81 & 0.53 & 0.57 & 0.11 & 0.26 & 0.66 \\
\hline Autoconsumo & & 3.13 & 23.60 & 9.11 & 3.39 & 8.39 & 1.70 & 0.75 & 19.63 & 8.40 & 4.59 & 2.31 & 0.69 & 0.41 \\
\hline Total & & 100.00 & 100.00 & 100.00 & 100.00 & 100.00 & 100.00 & 100.00 & 100.00 & 100.00 & 100.00 & 100.00 & 100.00 & 100,00 \\
\hline
\end{tabular}

Fuente: Secretaría de Programactón y Presupuasto, Coordinación General del Sístema Nacional de Informsción, "Encuesta Nacional de Ingrearo y Gastoo de los Hoga-

Nota: 1. j. Pestán el Cuadro A. 37).

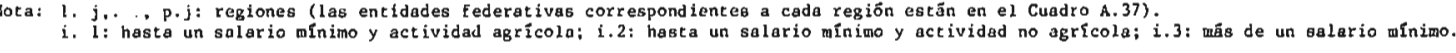


hogares agrícolas y no-agricolas), tiende a consumir proporcionalmente más productos derivados del maíz y menos de origen animal.

Hasta ahora se han presentado los patrones de consumo dentro de cada grupo socioeconómico. Para determinar cuáles son los productos de consumo popular también es conveniente conocer el comportamiento del gasto entre el grupo de hasta un salario minimo y el resto; los resultados se presentan en el Cuadro 9. Hemos definido como alimentos de consumo "popular" a aquellos en que el porcentaje consumido por el grupo objetivo es mayor o igual al $30 \% ; 14$ los productos que cumplen con esta condición son: mafz en grano $57.4 \%$; azúcar morena o piloncillo $41.9 \%$; manteca de puerco $40.3 \%$; harina de maíz $38.9 \%$; café molido o tostado $37.2 \%$; frijol $37.3 \%$; masa de maíz $34.6 \%$; azúcar blanca $32 \%$ y arroz $29.9 \%{ }^{15}$

Por otra parte, se han considerado productos de consumo "de lujo" is a aquellos en que la participación del grupo cbjetivo es menor o igual al quince por ciento y son los siguientes: legumbres y hortalizas procesadas $4.7 \%$; frutas procesadas $5.4 \%$; otros productos lácteos $6.1 \%$; queso amarillo $6.6 \%$; otros tipos de carne $6.7 \%$; soya $7.1 \%$; otros tipos de queso $8.4 \%$; otras frutas frescas $8.9 \%$; alimentos preparados para niños $8.0 \%$; cítricos $9.5 \%$; leche pasteurizada $10.3 \%$; dulces y postres $10.8 \%$; aguacate $11.3 \%$; pescados y mariscos frescos $11.5 \%$; jugos o néctares $12.2 \%$; carne seca de res $12.5 \%$; semillas $14.1 \%$; carne de res $14.2 \%$; carne de aves $14.7 \%$; chocolate, cocoa y tê $15 \%$ y otros azúcares y mieles $15.3 \%$.

Estos porcentajes indican que el mercado para la agroindustria moderna (la que produce los enlatados, por ejemplo) está constituido principalmente por el grupo que tiene ingresos superiores al salario mínimo.

\section{Impactos redistributivos}

1. Tendencias en los patrones de consumo a nivel nacional $y$ regional 37

En esta sección se analizan las tendencias en el consumo ante

34 Este límite se definió considerando que en el gasto total en alimentos, es el grupo de hasta un salario minimo participa con un $16.6 \%$ (véase Cuadro 12 ), aproximadamente la mitad de $30 \%$.

$15 \mathrm{El}$ porcentaje consumido por este grupo de ingreso en bebidas alcohólicas resultó igual a $40.1 \%$

16 Esta definición no está basada en las elasticidades-ingreso. Por lo tanto, una categorización de los bienes basada en éstas no tiene por qué coincidir con la que aquí presentamos.

17 Como las propensiones marginales al consumo se calculan con los patrones de consu- 
cambios en el ingreso. ${ }^{18}$ Para ello se han utilizado las propensiones marginales al consumo estimado, por región y a nivel nacional, que aparecen en los Cuadros 9 y 10 , respectivamente. ${ }^{19}$

En el caso de los resultados a nivel nacional, si el ingreso del grupo de hasta un salario mínimo aumentara, el incremento serfa destinado, en primer lugar, a alimentos y bebidas $\mathrm{y}$, en segundo, a vivienda; para el resto de los hogares, en cambio, la mayor parte del incremento en su ingreso se destinar fa a otros gastos, transporte y comunicaciones y vivienda; alimentos y bebidas ocuparfa el cuarto lugar en orden de importancia (véase Cuadro 9).

A nivel de los alimentos específicos, los hogares más pobres, consumirian relativamente más de los siguientes productos: tortillas de maíz, carne de res, leche, refrescos y sodas, huevos, carne de puerco, aceites y grasas vegetales, panes de todo tipo y quesos. Es interesante notar que, incluso para este grupo, el maíz en grano es un bien inferior; o sea, la tendencia a sustituir el maíz en grano por el maiz en su forma industrializada (tortillas de maí, por ejemplo), se deja notar aưn en niveles de bajos ingresos.

Por otro lado, el grupo de hogares que se ubica por encima del salario minimo, tendería a consumir relativamente más carne de res, leche pasteurizada, otros tipos de carne y carnes procesadas y frutas frescas. Como era previsible los productos de consumo primordialmente popular, para este grupo de hogares son bienes inferiores. 20

En cuanto a las tendencias a nivel regional, se observa lo siguiente (véase Cuadro 10). Para los siete grandes agregados 21 de bienes, las tendencias son: los hogares agrícolas del grupo objetivo asignan el incremento de su ingreso, principalmente, a consumir más alimentos; $y$, en cuanto al resto de este grupo de bienes, no se observa un patrón muy definido, excepto que el incremento del gasto en salud y en educación siempre es inferior al del resto. Para los hogares no agrícolas del grupo objetivo también el incremento principal se da en alimentos, pero menor que en los hogares agrícolas, ya que buena parte del aumento del ingreso se destina a gastos en vivienda. Para el

mo vigentes (i.e., la propensión media), este tipo de experimento sólo se aplica a los casos en que los cambios en el ingreso sean pequeños (marginales); si fueran grandes, la propensión media no sería constante $y$, por lo tanto, cambiarian las propensiones marginales.

18 En realidad, en este ejercicio se suponen cambios en el gasto total, en lugar de cambios en el ingreso.

19 Estas propensiones miden el cambio en el consumo del bien y ante cambios en el gasto total. E1 método utilizado para calcular dichas propensiones figura en el Apéndice metodológico.

20 Como es el caso de casi todos los derivados del maíz, frijol, azúcar morena, manteca de puerco y leche no pasteurizada.

21 Alimentos y bebidas, vestimenta, etc. 
Cuadro 9

Elasticidades-Gasto y propensiones marginales al consumo por grupo socioeconómico y para el total nacional

\begin{tabular}{|c|c|c|c|c|c|c|}
\hline \multirow[b]{2}{*}{ Rubro } & \multicolumn{2}{|c|}{$\mathrm{Y} \leq 1 \quad \mathrm{SM}$} & \multicolumn{2}{|c|}{$x>1$ SM } & \multicolumn{2}{|c|}{ Total Nacional } \\
\hline & $\begin{array}{l}\text { Elasticidad } \\
\text { Gasto } \\
\end{array}$ & $\begin{array}{c}\text { Propensibn } \\
\text { Margina } 1\end{array}$ & $\begin{array}{c}\text { Elasticidad } \\
\text { Gasto }\end{array}$ & $\begin{array}{c}\text { Propension } \\
\text { Marginal }\end{array}$ & $\begin{array}{c}\text { Elasticidad } \\
\text { Gasto }\end{array}$ & $\begin{array}{l}\text { Propension } \\
\text { Marginal }\end{array}$ \\
\hline $\begin{array}{l}\text { Alimentos y Bebidas } \\
\text { Vestimenta y Calzado } \\
\text { Vivienda } \\
\text { Educacion } \\
\text { Salud } \\
\text { Transportes y Comunicaciones } \\
\text { Otros Gastos }\end{array}$ & $\begin{array}{l}1.05607 \\
1.19938 \\
0.909657 \\
1.64642 \\
0.401869 \\
1.62773 \\
0.238318\end{array}$ & $\begin{array}{l}0.526959 \\
0.080598 \\
0.122364 \\
1.013454 \\
0.015959 \\
0.060929 \\
0.050997\end{array}$ & $\begin{array}{l}0.478312 \\
1.10199 \\
1.13130 \\
1.65768 \\
1.04220 \\
1.78429 \\
1.28605\end{array}$ & $\begin{array}{l}0.166764 \\
0.099464 \\
1.181803 \\
0.032385 \\
0.032724 \\
0.195080 \\
0.308805\end{array}$ & $\begin{array}{l}0.768862 \\
1.25629 \\
1.13533 \\
1.62515 \\
0.825150 \\
1.78323 \\
1.00000\end{array}$ & $\begin{array}{l}0.285571 \\
1.108283 \\
1.181468 \\
0.029359 \\
0.028084 \\
0.017410 \\
0.232506\end{array}$ \\
\hline $\begin{array}{l}\text { Maiz y sus productos } \\
\text { Tortillas de maiz } \\
\text { Masz en grano } \\
\text { Harina de måz } \\
\text { Nixtamal } \\
\text { Otros productos del masz }\end{array}$ & $\begin{array}{c}\mathrm{ns} \\
1.83801 \\
-1.09813 \\
\mathrm{~ns} \\
1.97196 \\
1.55607\end{array}$ & $\begin{array}{l}\mathrm{ns} \\
0.0466666 \\
-0.090053 \\
\mathrm{~ns} \\
0.005050 \\
0.005465\end{array}$ & $\begin{array}{l}-0.402110 \\
-0.166471 \\
-1.57444 \\
-0.805393 \\
-0.641266 \\
0.409144\end{array}$ & $\begin{array}{l}-0.011705 \\
-0.062957 \\
-0.009927 \\
-0.001094 \\
-0.000558 \\
0.001153\end{array}$ & $\begin{array}{l}-0.173653 \\
0.797605 \\
-1.39162 \\
\text { ns } \\
\text { ns } \\
0.904192\end{array}$ & $\begin{array}{l}-0.007258 \\
0.014921 \\
-0.023876 \\
\mathrm{~ns} \\
\mathrm{~ns} \\
0.002653\end{array}$ \\
\hline $\begin{array}{l}\text { Otros cereales } \\
\text { Pan dulce de caja y otros panes } \\
\text { Pan blanco } \\
\text { Pastas para sopas } \\
\text { Galletas } \\
\text { Harinas, tortillas y otros } \\
\text { Arroz, harina de arroz y avena }\end{array}$ & $\begin{array}{l}0.887850 \\
1.08723 \\
0.992212 \\
0.962617 \\
0.514019 \\
0.884735 \\
0.838006\end{array}$ & $\begin{array}{l}0.052884 \\
0.014972 \\
0.011482 \\
0.008086 \\
0.003459 \\
0.005816 \\
0.010491\end{array}$ & $\begin{array}{l}0.315358 \\
0.547479 \\
\mathrm{~ns} \\
-0.144197 \\
0.613130 \\
0.663540 \\
\mathrm{~ns}\end{array}$ & $\begin{array}{l}0.011797 \\
0.006467 \\
\mathrm{~ns} \\
-0.000526 \\
0.003176 \\
0.002869 \\
\mathrm{~ns}\end{array}$ & $\begin{array}{l}0.673054 \\
0.906587 \\
0.608383 \\
0.394012 \\
0.735329 \\
0.876647 \\
0.350898\end{array}$ & $\begin{array}{l}0.027068 \\
0.011053 \\
0.004821 \\
0.001712 \\
0.003858 \\
0.003844 \\
0.002148\end{array}$ \\
\hline $\begin{array}{l}\text { Carnes } \\
\text { Carne de res } \\
\text { Carne de puerco } \\
\text { Carne de aves } \\
\text { Carne seca de res } \\
\text { Otros tipos de carne } \\
\text { Manteca de puerco }\end{array}$ & $\begin{array}{l}1.60592 \\
1.42679 \\
0.602804 \\
1.29907 \\
\quad \mathrm{~ns} \\
1.92056 \\
\mathrm{~ns}\end{array}$ & $\begin{array}{l}0.211997 \\
0.056338 \\
0.009599 \\
1.019750 \\
\mathrm{~ns} \\
0.007307 \\
\mathrm{~ns}\end{array}$ & $\begin{array}{r}0.750293 \\
0.726846 \\
0.451348 \\
0.524033 \\
0.997655 \\
1.48652 \\
-0.565064\end{array}$ & $\begin{array}{r}0.087215 \\
0.031147 \\
0.005489 \\
0.008182 \\
0.000531 \\
0.014027 \\
-0.002687\end{array}$ & $\begin{array}{l}1.13174 \\
1.12814 \\
0.773653 \\
1.03952 \\
1.06467 \\
1.71617 \\
-0.149701\end{array}$ & $\begin{array}{l}0.131224 \\
0.047717 \\
0.009619 \\
1.015629 \\
0.000552 \\
0.014953 \\
0.000972\end{array}$ \\
\hline Aceites y grasas vegetales & 0.724299 & 0.018281 & 0.239156 & 0.002823 & 0.463473 & 0.006464 \\
\hline $\begin{array}{l}\text { Leche y derivados } \\
\text { Leche bronca } \\
\text { Leche pasteurizada } \\
\text { Leche en polvo } \\
\text { Otros tipos de leche } \\
\text { Queso fresco } \\
\text { Queso amarillo } \\
\text { Otros tipos de queso } \\
\text { Mantequilla y crema } \\
\text { Otros productos 1acteos }\end{array}$ & $\begin{array}{l}1.76791 \\
1.54206 \\
2.39875 \\
0.933022 \\
1.88629 \\
2.14174 \\
\quad \mathrm{~ns} \\
1.46262 \\
2.01713 \\
\quad \mathrm{~ns}\end{array}$ & $\begin{array}{l}0.091505 \\
0.028573 \\
0.030957 \\
0.003078 \\
0.012766 \\
0.013615 \\
\text { ns } \\
0.002435 \\
0.002760 \\
\text { ns }\end{array}$ & $\begin{array}{r}0.595545 \\
-0.262603 \\
0.928488 \\
n s \\
0.309496 \\
0.415006 \\
1.32005 \\
1.30832 \\
1.03283 \\
1.45487\end{array}$ & $\begin{array}{r}0.030244 \\
-0.002553 \\
0.019665 \\
\text { ns } \\
1.001539 \\
0.002099 \\
0.000868 \\
0.003971 \\
0.003194 \\
0.001634\end{array}$ & $\begin{array}{l}1.12455 \\
0.529341 \\
1.59760 \\
0.524551 \\
0.978443 \\
0.972455 \\
1.30659 \\
1.42036 \\
1.67305 \\
1.35689\end{array}$ & $\begin{array}{l}0.056875 \\
0.005584 \\
0.033216 \\
0.001087 \\
0.005061 \\
0.004825 \\
0.000693 \\
0.003899 \\
0.004684 \\
0.001250\end{array}$ \\
\hline Huevo & 1.38318 & 0.026337 & 0.382181 & 0.005716 & 0.87065 & 0.013393 \\
\hline
\end{tabular}


Cuadro 9

(continuacion)

\begin{tabular}{|c|c|c|c|c|c|c|}
\hline \multirow[b]{2}{*}{ Rubro } & \multicolumn{2}{|c|}{$Y \leq 1 \quad S M$} & \multicolumn{2}{|c|}{$y>1$ SM } & \multicolumn{2}{|c|}{ Total Nacional } \\
\hline & $\begin{array}{l}\text { Elasticidad } \\
\text { Gasto }\end{array}$ & $\begin{array}{l}\text { Propension } \\
\text { Marginal }\end{array}$ & $\begin{array}{l}\text { Elasticitad } \\
\text { Gasto }\end{array}$ & $\begin{array}{l}\text { Propension } \\
\text { Marginal }\end{array}$ & $\begin{array}{c}\text { Elasticidad } \\
\text { Gasto }\end{array}$ & $\begin{array}{l}\text { Propension } \\
\text { Marginal } \\
\end{array}$ \\
\hline $\begin{array}{l}\text { Legumbres, feculentas y hortalizas } \\
\text { Frijol } \\
\text { Tomate fresco } \\
\text { Chile } \\
\text { Papas, camote y otras feculentas } \\
\text { otras lequmbres y hortalizas frescas } \\
\text { Legumbres y hortalizas procesadas }\end{array}$ & $\begin{array}{r}0.468847 \\
0.299065 \\
0.534268 \\
-0.191589 \\
1.02960 \\
0.872274 \\
1.13396\end{array}$ & $\begin{array}{r}0.035580 \\
0.009326 \\
0.008546 \\
-0.001313 \\
0.008354 \\
0.009322 \\
0.003390\end{array}$ & $\begin{array}{r}0.246190 \\
-0.344666 \\
0.226260 \\
0.229777 \\
0.101993 \\
0.652889 \\
0.861665\end{array}$ & $\begin{array}{r}0.009182 \\
-0.003214 \\
0.001993 \\
0.000644 \\
0.000413 \\
0.005836 \\
0.002904\end{array}$ & $\begin{array}{l}0.426347 \\
\text { ns } \\
0.497006 \\
0.239521 \\
0.501796 \\
0.844311 \\
1.18323\end{array}$ & $\begin{array}{l}0.018167 \\
\text { ns } \\
0.004845 \\
0.000795 \\
0.002348 \\
0.007618 \\
0.003858\end{array}$ \\
\hline $\begin{array}{l}\text { Frutas } \\
\text { Platanos } \\
\text { Citricos } \\
\text { Aguacate } \\
\text { Otras frutas frescas } \\
\text { Frutas procesadas }\end{array}$ & $\begin{aligned} 1.35358 \\
0.989097 \\
1.73832 \\
1.54829 \\
1.49377 \\
-155.763\end{aligned}$ & $\begin{array}{r}0.020641 \\
0.005138 \\
0.003887 \\
0.003445 \\
0.008140 \\
-0.029426\end{array}$ & $\begin{array}{l}0.903869 \\
0.314185 \\
1.12778 \\
0.670574 \\
1.11489 \\
1.32825\end{array}$ & $\begin{array}{l}0.019120 \\
0.001223 \\
0.004286 \\
0.001809 \\
0.011326 \\
0.000916\end{array}$ & $\begin{array}{l}1.24551 \\
0.760479 \\
1.46228 \\
1.31737 \\
1.41078 \\
1.21916\end{array}$ & $\begin{array}{l}0.024036 \\
0.003037 \\
0.005082 \\
0.003273 \\
0.012356 \\
0.000789\end{array}$ \\
\hline $\begin{array}{l}\text { AzǴar y derivados } \\
\text { Azbcar blanca } \\
\text { AzGcar morena, piloncillo } \\
\text { Dulces y postres } \\
\text { Refrescos y sodas } \\
\text { Jugos o néctares } \\
\text { Miel } \\
\text { Otros azlicares y mieles }\end{array}$ & $\begin{array}{c}0.552960 \\
\text { ns } \\
-0.414330 \\
1.55296 \\
1.36449 \\
1.01869 \\
\star * \\
\star \star\end{array}$ & $\begin{array}{c}0.025317 \\
\text { ns } \\
-0.005148 \\
0.006590 \\
0.026410 \\
0.001092 \\
\star * \\
\star *\end{array}$ & $\begin{array}{l}0.334115 \\
n s \\
-0.357562 \\
0.798359 \\
0.280188 \\
1.01993 \\
1.40680 \\
\$\end{array}$ & $\begin{array}{c}0.009056 \\
\text { ns } \\
-0.000968 \\
0.004784 \\
0.003893 \\
0.001396 \\
0.000463 \\
\star \star\end{array}$ & $\begin{array}{r}0.590419 \\
0.147305 \\
-0.211976 \\
1.36048 \\
0.826347 \\
1.30778 \\
1.08144 \\
\star \star\end{array}$ & $\begin{array}{r}0.017327 \\
0.000538 \\
-0.000850 \\
0.007516 \\
0.012303 \\
0.001662 \\
0.000297 \\
\star \star\end{array}$ \\
\hline $\begin{array}{l}\text { Pescados y mariscos frescos } \\
\text { pescados y mariscos procesados }\end{array}$ & $\begin{array}{l}1.61059 \\
0.755452\end{array}$ & $\begin{array}{l}0.006647 \\
0.002333\end{array}$ & $\begin{array}{l}0.807737 \\
1.01993\end{array}$ & $\begin{array}{l}0.004469 \\
0.002550\end{array}$ & $\begin{array}{l}1.23353 \\
0.840719\end{array}$ & $\begin{array}{l}0.006420 \\
0.002053\end{array}$ \\
\hline $\begin{array}{l}\text { Otros alimentos } \\
\text { Soya } \\
\text { Especias y aderezos } \\
\text { Cafê tostado o molido } \\
\text { Cafe soluble o instántaneo } \\
\text { Chocolate, cocoa y tê } \\
\text { Alimentos prenarados para niños } \\
\text { Bebidas alcohrilicas } \\
\text { Semillas }\end{array}$ & $\begin{array}{l}0.450156 \\
* * \\
0.398754 \\
\mathrm{~ns} \\
1.28860 \\
0.922118 \\
\mathrm{~ns} \\
0.562305 \\
\mathrm{~ns}\end{array}$ & $\begin{array}{l}0.038118 \\
0 * * \\
0.003882 \\
\mathrm{~ns} \\
0.005771 \\
0.002764 \\
\mathrm{~ns} \\
0.007517 \\
\mathrm{~ns}\end{array}$ & $\begin{array}{l}0.423212 \\
\mathrm{~ns} \\
0.481829 \\
\mathrm{~ns} \\
0.540445 \\
0.534584 \\
0.827667 \\
0.882767 \\
1.12075\end{array}$ & $\begin{array}{l}0.020040 \\
\text { ns } \\
0.002980 \\
\text { ns } \\
0.002344 \\
0.001488 \\
0.000790 \\
0.009882 \\
0.000650\end{array}$ & $\begin{array}{l}0.547305 \\
0.374850 \\
0.602395 \\
\text { ns } \\
0.998802 \\
0.916168 \\
1.18683 \\
0.838323 \\
1.04192\end{array}$ & $\begin{array}{l}0.002852 \\
0.000032 \\
0.003919 \\
\text { ns } \\
0.004487 \\
0.002564 \\
0.001016 \\
0.008542 \\
0.000589\end{array}$ \\
\hline Autoconsumo & -1.32243 & -0.109725 & -0.452521 & -0.003367 & -0.935329 & -0.016174 \\
\hline Alimentos consumidos fuera del hogar & 1.78349 & 0.028576 & 1.46190 & 0.055331 & 1.69581 & 0.057380 \\
\hline
\end{tabular}

Fuente: Secretarfa de programaci6n y Presupuesto, Coordinaci6n General del Sistema Nacional de Informacín, "Encuesta Nacional de Ingresos y Gastos de los Hogares, 1977".

Nota: El metodo usado para calcular las elasticidades y las propensiones viene en la seccín A.2 del Apendice Metodol6gico. 
resto de los hogares el incremento del ingreso de destina, principalmente, a alimentos, vivienda, transporte y comunicaciones y otros gastos; en este grupo el incremento del gasto en alimentos es en algunas regiones igual y hasta inferior al asignado a los otros bienes. (Véase, por ejemplo, las regiones $2.3,5.3,6.3$ y 9.3 en el Cuadro 10).

En cuanto a los alimentos especificos, resulta que -en generalpara los tres grupos y para todas las regiones, los aumentos del ingreso se destinan más a productos de origen animal (carne de res, sobre todo) que a cereales y sus productos (maíz, trigo y arroz).

Entre los productos del maíz, las tortillas tienen la propensión marginal al consumo, más alta en prácticamente todos los casos. Maíz en grano mostró una propensión no significativa en muchos de los grupos y regiones, y en otros el número de casos resultó insuficiente para efectuar la estimación.22 Sólo en el caso de los hogares del grupo objetivo de las regiones 4, 5, 6 y 8 la propensión marginal al consumo del maíz en grano resultó más o menos igual, o incluso superior, a la de tortillas de maíz. El lector recordará que estas regiones presentan el nivel de pobreza mayor.

En el caso del grupo objetivo, para casi todas las regiones, los productos con propensiones al consumo más altas (aparte del caso de carne de res y de huevo, y del de tortillas de maíz y de maíz en grano, que ya mencionamos) son: pan dulce, de caja y otros panes; pasta para sopas; arroz; aceites y grasas vegetales; leche bronca; frijol; tomate fresco, y refrescos y sodas. La mayor parte de estos bienes, como se ha visto anteriormente, son también los más importantes en las canastas de consumo actual; o sea que, según nuestros resultados, la tendencia en los patrones de consumo del grupo objetivo - ante cambios en su ingreso-implica que no se modificarían en mayor grado los hábitos actuales.

\section{Impactos redistributivos a nivel nacional y regional}

La comparación de las propensiones marginales al consumo entre grupos socioeconómicos, permite evaluar el impacto de una redistribución hacia los hogares más pobres sobre la demanda de bienes.

A nivel nacional, si se incrementara el ingreso de los hogares de hasta un salario mínimo en un monto superior al del resto de los

\footnotetext{
22 Para el grupo objetivo esto puede ser consecuencia del nivel de autoconsumo de maíz en grano, que la encuesta no contabiliza por separado del resto del autoconsumo; para el resto de los hogares la auscncia de información sobre consumo de maíz en grano puede reflejar la desaparición de este bien de su canasta de consumo.
} 
Cuadro 10

Propensiones marginales al consumo por region y grupo: 1977

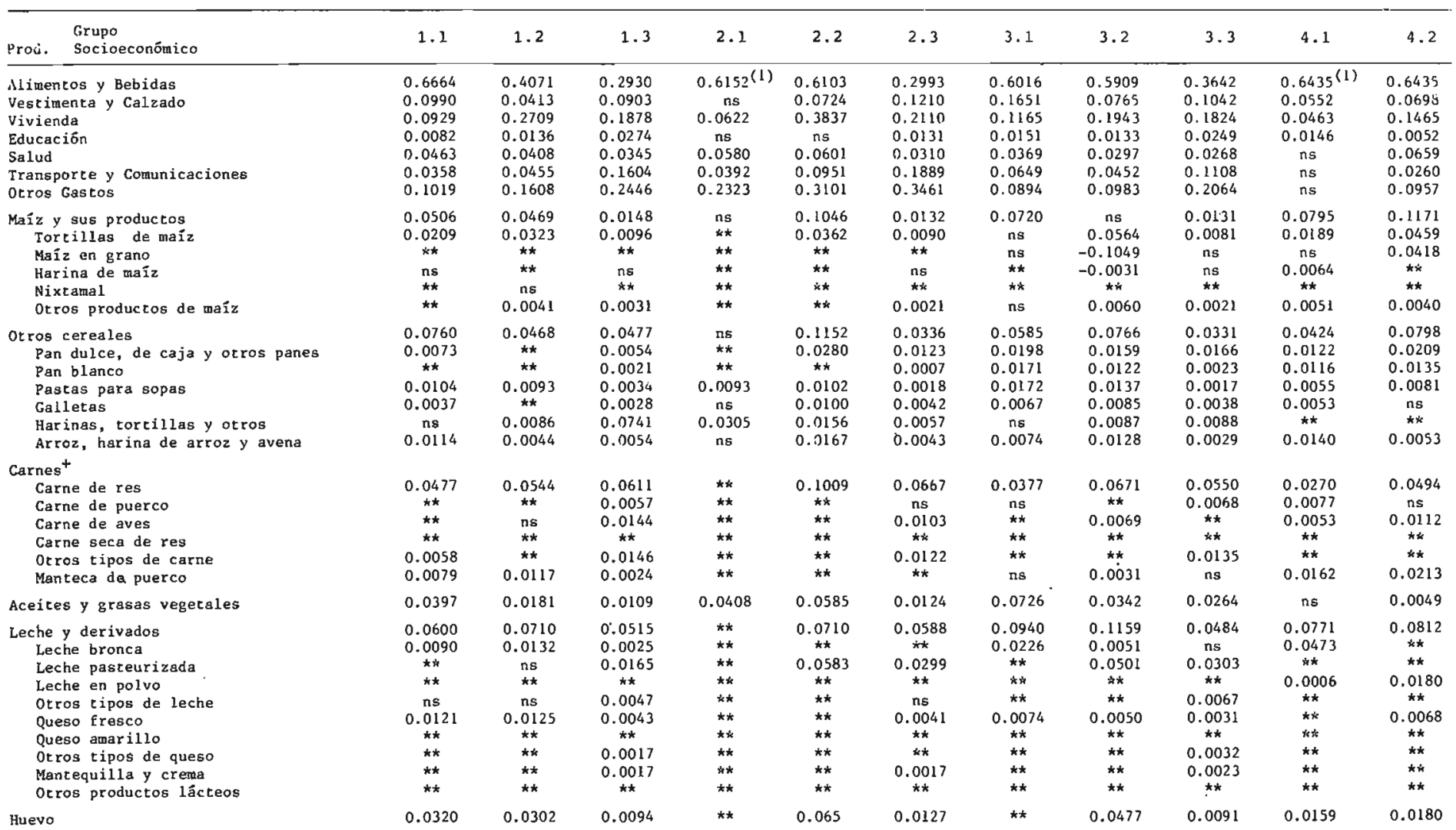


(continuacion)

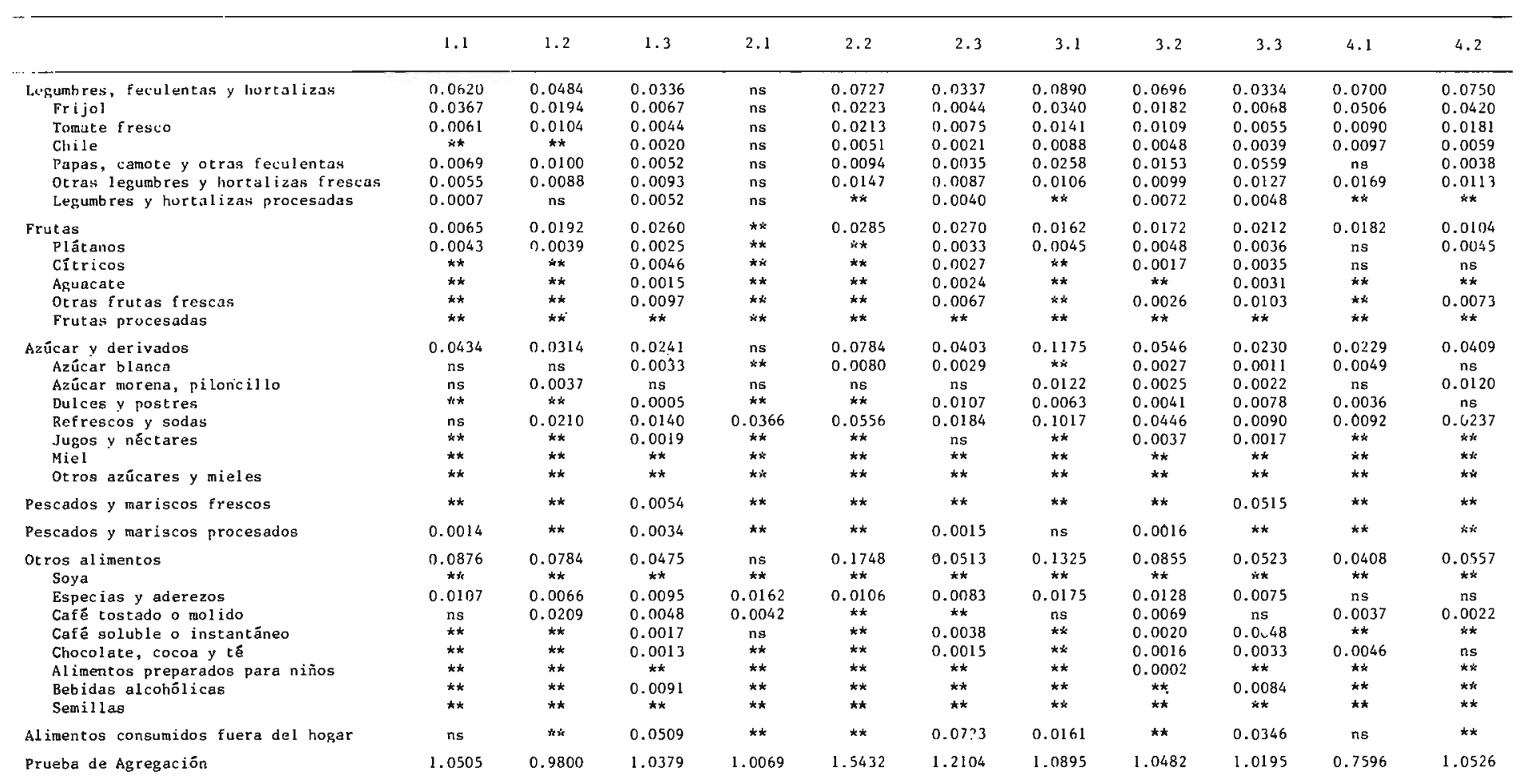


Cuadro 10

(continuacion)

\begin{tabular}{|c|c|c|c|c|c|c|c|c|c|c|}
\hline & 4.3 & $5.1(1)$ & 5.2 & 5.3 & 6.1 (1) & 6.2 & 6.3 & 7.1 & 7.2 & 7.3 \\
\hline Alimentos y Bebidas & 0.4148 & 0.6500 & 0.6335 & 0.2300 & 0.6000 & 0.4641 & 0.2197 & 0.7783 & 0.5851 & 0.4177 \\
\hline Vestimenta y Calzado & 0.0892 & 0.0741 & 0.0696 & 0.1238 & 0.1044 & 0.1523 & 0.1063 & 0.0711 & 0.0074 & 0.0622 \\
\hline $\begin{array}{l}\text { Vivienda } \\
\text { vacula }\end{array}$ & 0.1938 & 0.0539 & 0.1515 & 0.1269 & 0.0567 & 0.2015 & 0.1184 & 0.0502 & 0.1622 & 0.4021 \\
\hline Educación & 0.0118 & 0.0106 & 0.0151 & 0.0215 & 0.0053 & 0.0108 & 0.0996 & ns & ns & 0.0258 \\
\hline Salud & 0.0453 & 0.0343 & 0.0308 & 0.0357 & 0.0629 & 0.0480 & 0.0153 & ns & 0.0258 & 0.0168 \\
\hline Transporte y Comunicaciones & 0.0933 & 0.0412 & 0.0347 & 0.1656 & 0.0635 & 0.0565 & 0.1841 & 0.0538 & 0.0382 & 0.2880 \\
\hline 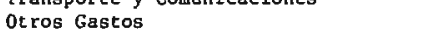 & 0.2336 & 0.0965 & 0.1204 & 0.2628 & ns & 0.1592 & 0.2947 & 0.0888 & 0.1662 & 0.3204 \\
\hline Maiz y sus productos & 0.0216 & 0.0580 & 0.0617 & ns & 0.1714 & ns & ns & 0.1221 & ns & ns \\
\hline Tortillas de maíz & 0.0121 & $* *$ & 0.0211 & 0.0081 & $* *$ & 0.0210 & ns & 0.0488 & $\mathrm{~ns}$ & ns \\
\hline & ns & 0.0469 & ns & ns & 0.1426 & ns & ns & ns & ns & ns \\
\hline Harina de maíz & $* *$ & $\star \star *$ & $* \star$ & $\star \star \star \star$ & $* *$ & ** & $* *$ & ** & $* *$ & $\star * *$ \\
\hline Nixtamal & $\star *$ & ** & $\star *$ & & $0.000 \mathrm{l}$ & ** & ns & ** & ** & ** \\
\hline otros productos de maíz & ns & ns & $\star *$ & 0.0012 & $* \star$ & $\star * *$ & ** & ** & ** & ** \\
\hline Otros cereales & 0.0270 & 0.0623 & 0.0880 & 0.0267 & 0.0824 & 0.0426 & 0.0174 & 0.1218 & 0.0570 & 0.0364 \\
\hline Pan dulce, de caja y otros panes & 0.0086 & 0.0246 & 0.0292 & 0.0130 & 0.0068 & ns & 0.0106 & ns & 0.0025 & 0.0069 \\
\hline Pan blanco & 0.0049 & 0.0188 & 0.0261 & 0.0077 & 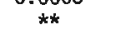 & ns & ns & 0.0497 & 0.0289 & ns \\
\hline Pastas para sopas & 0.0016 & 0.0115 & 0.0150 & 0.0022 & 0.0073 & 0.0062 & 0.0017 & 0.0030 & 0.0009 & 0.0010 \\
\hline Galletas & ns & ns & $\mathrm{ns}$ & 0.0020 & 0.0106 & ns & 0.0061 & 0.0444 & ns & 0.0072 \\
\hline Harinas, tortillas y otros & 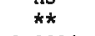 & ns & $* \star$ & $\pi *$ & $* *$ & $* *$ & $* \pi$ & $* *$ & ** & 0.0015 \\
\hline Arroz, harina de arroz y avera & 0.0014 & 0.0127 & 0.0181 & 0.0023 & 0.0249 & 0.0124 & ns & 0.0345 & ns & 0.0062 \\
\hline \multicolumn{11}{|l|}{ Carnes $^{+}$} \\
\hline Carne de res & 0.0298 & 0.0246 & 0.0278 & 0,0322 & 0.0469 & ns & 0.0235 & 0.0737 & 0.0560 & 0.0385 \\
\hline Carne de puerco & 0.0085 & 0.0213 & 0.0148 & 0.0105 & ns & ns & ns & 0.1119 & 0.0592 & 0.0407 \\
\hline Carne de aves & 0.0096 & ng & 0.0149 & 0.0147 & ns & 0.0405 & 0.0224 & 0.0344 & 0.0098 & 0.0289 \\
\hline Carne sece de res & $* *$ & $\star * *$ & ** & $\star *$ & $* *$ & $k \pi$ & $* * *$ & $\star x *$ & $* *$ & $\pi_{k \pi}$ \\
\hline otros tipos de carne & 0.0034 & $\star *$ & ** & 0.0119 & 0.0008 & ** & 0.0074 & ** & ** & 0.0146 \\
\hline Mantecs de puerco & 0.0045 & 0.0137 & ns & 0.0029 & 0.0110 & ns & $\star \star \star *$ & 0.0429 & 0.0100 & 0.0028 \\
\hline Acartes y grasas vegetales & 0.0014 & 0.0070 & 0.0403 & 0.0057 & 0.0124 & 0.0163 & 0.005 .1 & ns & 0.0236 & 0.0123 \\
\hline Leche y derivados & 0.0594 & 0.0249 & 0.0891 & 0.0379 & 0.0158 & 0.0511 & 0.0216 & 0.0345 & 0.0116 & 0.0765 \\
\hline Leche bronca & 0.0272 & $\underset{\star \star}{0.0069}$ & 0.0547 & 0.0097 & $\begin{array}{l}* \star \\
\star \star\end{array}$ & 0.0187 & ns & $\stackrel{* *}{* *}$ & $\begin{array}{l}* * \\
* *\end{array}$ & $* * *$ \\
\hline & $\underset{* *}{0.0053}$ & $\begin{array}{l}* * \\
* *\end{array}$ & $\underset{* \pi}{n s}$ & $\underset{* *}{0.0136}$ & 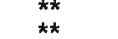 & $\begin{array}{l}\star \star \\
* *\end{array}$ & $\begin{array}{l}* \star \\
* *\end{array}$ & 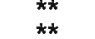 & $\begin{array}{c}* \star \\
* \star\end{array}$ & $\begin{array}{c}0.0053 \\
* \pi\end{array}$ \\
\hline $\begin{array}{l}\text { Leche en polvo } \\
\text { Otros tipos de leche }\end{array}$ & $* *$ & ** & ** & 0.0018 & ns & $* *$ & ns & ns & $* *$ & 0.0190 \\
\hline Queso fresco & 0.0015 & ns & $* *$ & 0.0039 & 0.0033 & $* *$ & 0.0068 & $* \dot{*}$ & $* *$ & $* *$ \\
\hline Queso amarillo & $* *$ & ** & ** & $* *$ & $\star * *$ & $* *$ & $* *$ & $* *$ & ** & 0.0025 \\
\hline Otros tipos de queso & ns & $\star * *$ & $\star * *$ & 0.0013 & $* *$ & ** & $* *$ & ** & $\star *$ & $\pi x$ \\
\hline Mantequilla y crema & 0.0014 & ** & $* *$ & 0.0031 & $* *$ & ** & ** & $* *$ & ** & 0.0014 \\
\hline Otros productos lâcteos & $* *$ & ** & ** & $* *$ & ** & ** & ** & ** & ** & $* *$ \\
\hline Huevo & 0.0066 & 0.0187 & 0.0224 & 0.0120 & ns & ns & 0.0083 & 0.0330 & ns & 0.0188 \\
\hline
\end{tabular}


(continuacion)

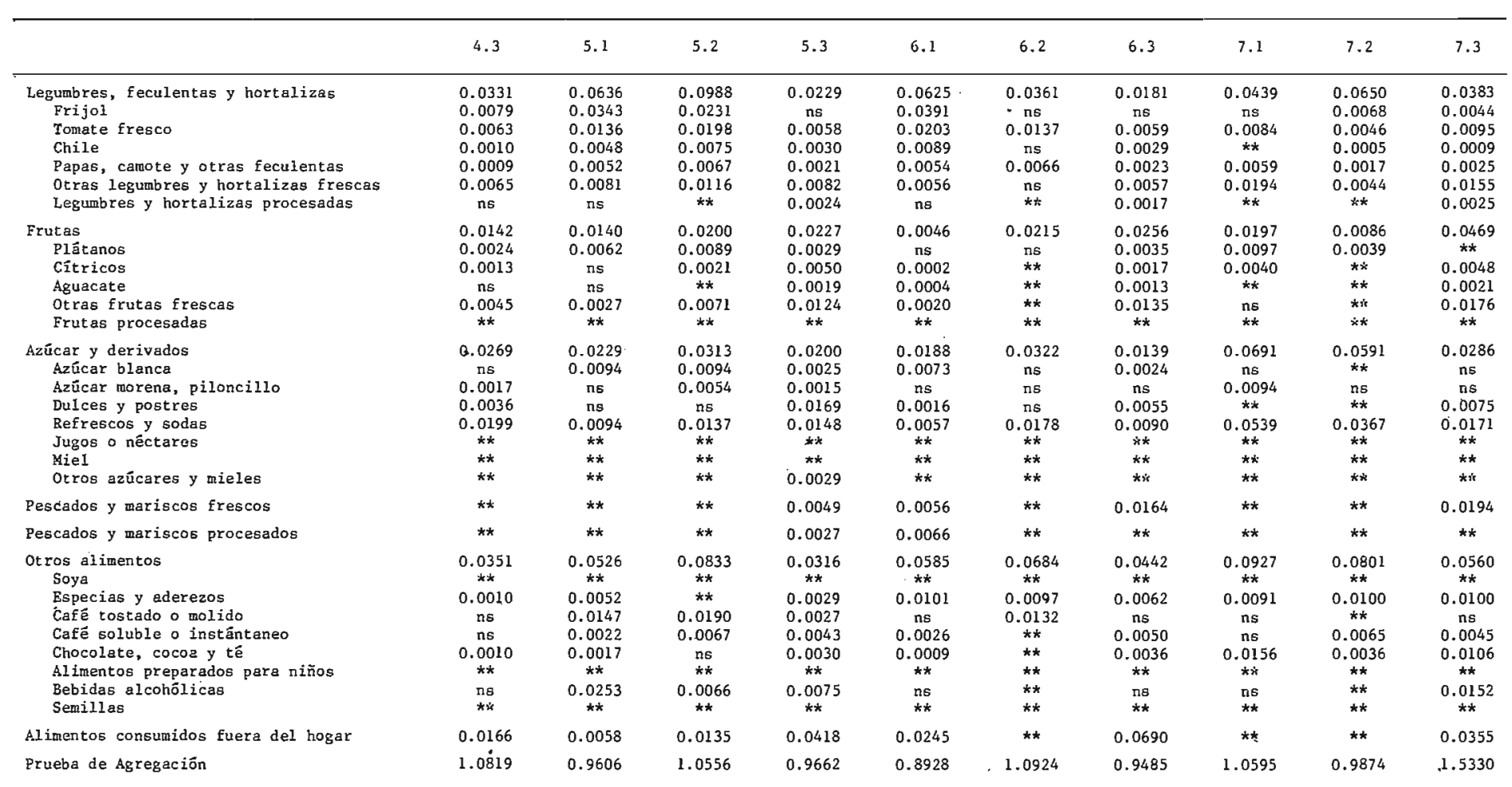


Cuadro 10

(continuacion)

\begin{tabular}{|c|c|c|c|c|c|c|}
\hline & $8.1 \quad(1)$ & 8.2 & 8.3 & 9.1 & 9.2 & 9.3 \\
\hline $\begin{array}{l}\text { Alimentos y Bebidas } \\
\text { Vestimenta y Calzado } \\
\text { Vivienda } \\
\text { Educacín } \\
\text { Salud } \\
\text { Transporte y Comunicaciones } \\
\text { Otros Gastos }\end{array}$ & $\begin{array}{l}0.6227 \\
0.0961 \\
0.0840 \\
0.0126 \\
0.0319 \\
0.0364 \\
0.1503\end{array}$ & $\begin{array}{l}0.4759 \\
0.0688 \\
0.1783 \\
0.0191 \\
0.0276 \\
0.0321 \\
0.2355\end{array}$ & $\begin{array}{l}0.4300 \\
0.0728 \\
0.1521 \\
0.0111 \\
0.0290 \\
0.1309 \\
0.2335\end{array}$ & $\begin{array}{l}0.4202 \\
0.1252 \\
0.0716 \\
\star \star \\
-0.0081 \\
0.1089 \\
0.2554\end{array}$ & $\begin{array}{l}0.5247 \\
0.0613 \\
0.2148 \\
0.0106 \\
0.0192 \\
0.0644 \\
0.2000\end{array}$ & $\begin{array}{l}0.1871 \\
0.0920 \\
0.1896 \\
0.0419 \\
0.0333 \\
0.1657 \\
0.3040\end{array}$ \\
\hline $\begin{array}{l}\text { Maíz y sus productos } \\
\text { Tortillas de maíz } \\
\text { MaYz en grano } \\
\text { Harina de maíz } \\
\text { Nixtamal } \\
\text { Otros productos dél maíz }\end{array}$ & $\begin{array}{l}0.0989 \\
k * \\
0.0760 \\
k * \\
k * \\
0.0045\end{array}$ & $\begin{array}{l}0.0773 \\
0.0419 \\
\mathrm{~ns} \\
* * \\
* * \\
n \mathrm{~s}\end{array}$ & $\begin{array}{l}0.0291 \\
0.0108 \\
n s \\
* * \\
* * \\
0.0014\end{array}$ & $\begin{array}{l}\mathrm{ns} \\
\mathrm{ns} \\
4 * \\
k * \\
k * \\
k *\end{array}$ & $\begin{array}{l}0.0689 \\
0.0546 \\
\text { ns } \\
\text { ns } \\
0.0017 \\
0.0029\end{array}$ & $\begin{array}{l}n s \\
n s \\
n s \\
n s \\
n s \\
0.0012\end{array}$ \\
\hline $\begin{array}{l}\text { Otros cereales } \\
\text { Pan dulce, de caja y otros panes } \\
\text { Pan blanco } \\
\text { Pasta para sopas } \\
\text { Galletas } \\
\text { Harinas, tortillas y otros } \\
\text { Arroz, harina de arroz y avena }\end{array}$ & $\begin{array}{l}0.0640 \\
0.0262 \\
0.0074 \\
0.0084 \\
0.0046 \\
\star \star \\
0.0182\end{array}$ & $\begin{array}{l}0.0673 \\
0.0381 \\
n s \\
0.0055 \\
0.0086 \\
* \hbar \\
0.0146\end{array}$ & $\begin{array}{l}0.0293 \\
0.0108 \\
0.0019 \\
0.0012 \\
\mathrm{~ns} \\
\mathrm{k} \\
0.0027\end{array}$ & $\begin{array}{l}0.0687 \\
\star * \\
0.0062 \\
* * \\
* * \\
* * \\
* *\end{array}$ & $\begin{array}{l}0.0646 \\
0.0249 \\
0.0166 \\
0.0095 \\
0.0032 \\
0.0020 \\
0.0101\end{array}$ & $\begin{array}{l}0.0137 \\
0.0065 \\
\text { ns } \\
\text { ns } \\
0.0023 \\
0.0022 \\
0.0012\end{array}$ \\
\hline $\begin{array}{l}\text { Carnest } \\
\text { Carne de res } \\
\text { Carne de puerco } \\
\text { Carne de aves } \\
\text { Carne seca de res } \\
\text { Orros tipos de carne } \\
\text { Manteca de puerco }\end{array}$ & $\begin{array}{l}0.0521 \\
0.0159 \\
n s \\
* * \\
* * \\
n s\end{array}$ & $\begin{array}{l}0.0680 \\
0.0211 \\
0.0173 \\
* * \\
* * \\
0.0057\end{array}$ & $\begin{array}{l}0.0403 \\
0.0091 \\
0.0205 \\
0.0014 \\
0.0068 \\
n \mathrm{~ns}\end{array}$ & $\begin{array}{l}* * \\
* * \\
* * \\
* * \\
* * \\
* *\end{array}$ & $\begin{array}{l}0.0517 \\
0.0188 \\
0.0149 \\
* * \\
0.0034 \\
0.0048\end{array}$ & $\begin{array}{l}0.0317 \\
0.0082 \\
* * \\
0.0002 \\
0.0139 \\
\mathrm{~ns}\end{array}$ \\
\hline Aceites y grasas vegetales & 0.0401 & 0.0212 & 0.0072 & ** & 0.0234 & 0.0040 \\
\hline $\begin{array}{l}\text { Leclee y derivados } \\
\text { Leche bronca } \\
\text { Leche pasteurizada } \\
\text { Leche en polvo } \\
\text { Orros ripos de leche } \\
\text { Queso Eresco } \\
\text { Rueso amarillo } \\
\text { Otros tipos de queso } \\
\text { Mantequilla y crema } \\
\text { Otros productos lácteos }\end{array}$ & $\begin{array}{l}0.0888 \\
n s \\
* * \\
* * \\
* * \\
0.0129 \\
* * \\
* * \\
* * \\
* *\end{array}$ & $\begin{array}{l}0.1124 \\
0.0245 \\
n s \\
* * \\
* * \\
0.0134 \\
* * \\
* * \\
* * \\
* *\end{array}$ & $\begin{array}{l}0.0502 \\
0.0077 \\
0.0095 \\
* * \\
n s \\
0.0076 \\
k * \\
n s \\
0.0016 \\
k *\end{array}$ & $\begin{array}{l}0.0954 \\
* * \\
* * \\
* * \\
* * \\
* * \\
* * \\
* * \\
* * \\
* *\end{array}$ & $\begin{array}{l}0.0801 \\
0.0126 \\
0.0352 \\
* * \\
0.0074 \\
0.0032 \\
* * \\
0.0014 \\
\text { n s } \\
* *\end{array}$ & $\begin{array}{l}0.0341 \\
0.0013 \\
0.0173 \\
\star * \\
0.0026 \\
0.0014 \\
0.0003 \\
0.0050 \\
0.0034 \\
0.0017\end{array}$ \\
\hline Huevo & 0.0191 & 0.0292 & 0.0106 & 0.0236 & 0.0248 & 0.0063 \\
\hline
\end{tabular}




\begin{tabular}{|c|c|c|c|c|c|c|}
\hline & 8.1 & 8.2 & 8.3 & 9.1 & 9.2 & 9.3 \\
\hline $\begin{array}{l}\text { Legumbres, feculentas y hortalizas } \\
\text { Frijol } \\
\text { Tomate fresco } \\
\text { Chile } \\
\text { Papas, camote y otras feculentas } \\
\text { otras legumbres y hortalizas frescas } \\
\text { Legumbres y hortalizas procesadas }\end{array}$ & $\begin{array}{l}0.0539 \\
0.0224 \\
0.0123 \\
n s \\
0.0071 \\
0.0104 \\
\text { ns }\end{array}$ & $\begin{array}{l}0.0402 \\
0.0224 \\
0.0112 \\
\text { ns } \\
0.0059 \\
0.0145 \\
\text { ns }\end{array}$ & $\begin{array}{l}0.0350 \\
0.0029 \\
0.0058 \\
0.0011 \\
0.0014 \\
0.0078 \\
0.0022\end{array}$ & $\begin{array}{l}0.0680 \\
0.0162 \\
0.0210 \\
k \star \\
* k \\
0.0132 \\
\star \star \star\end{array}$ & $\begin{array}{l}0.0692 \\
0.0240 \\
0.0160 \\
0.0045 \\
0.0069 \\
0.0153 \\
0.0018\end{array}$ & $\begin{array}{l}0.0091 \\
\mathrm{~ns} \\
0.0030 \\
0.0008 \\
0.0010 \\
0.0060 \\
0.0024\end{array}$ \\
\hline $\begin{array}{l}\text { Erutaz } \\
\text { P1atanos } \\
\text { CItricos } \\
\text { Aguacate } \\
\text { Otres frutas fresces } \\
\text { Frutas procesadas }\end{array}$ & $\begin{array}{l}0.0208 \\
0.0047 \\
k \star \\
k \star \\
0.0080 \\
k \star\end{array}$ & $\begin{array}{l}0.0155 \\
0.0071 \\
n s \\
\star * \\
0.0068 \\
\star \star\end{array}$ & $\begin{array}{l}0.0199 \\
0.0022 \\
0.0016 \\
0 \mathrm{ng} \\
0.0087 \\
\star \star\end{array}$ & $\begin{array}{l}\mathrm{ns} \\
\star * \\
k \star \\
k \star \\
k \star \\
k \star\end{array}$ & $\begin{array}{l}0.0214 \\
0.0042 \\
0.0037 \\
0.0022 \\
0.0106 \\
\star \star \star\end{array}$ & $\begin{array}{l}0.0170 \\
0.0013 \\
0.0037 \\
0.0018 \\
0.0095 \\
0.0007\end{array}$ \\
\hline $\begin{array}{l}\text { Azúcar y derivados } \\
\text { Azúcar blanca } \\
\text { Azúcar morena, piloncillo } \\
\text { Dulces y postres } \\
\text { ReErescos y sodas } \\
\text { Jugoo o néctares } \\
\text { Miel } \\
\text { Otros azúcares y ríeles }\end{array}$ & $\begin{array}{l}0.0390 \\
0.0087 \\
0.0068 \\
0.0041 \\
0.0255 \\
k * \\
* * \\
* *\end{array}$ & $\begin{array}{l}0.0392 \\
n s \\
n s \\
0.0070 \\
0.0282 \\
k \star k \\
k * \\
k *\end{array}$ & $\begin{array}{l}0.0239 \\
0.0020 \\
n 8 \\
0.0024 \\
0.0114 \\
\star \star \\
* \star \\
\star \star\end{array}$ & $\begin{array}{c}0.0633 \\
k * \\
n 5 \\
k \star \\
k * \\
k \star \\
k * \\
k *\end{array}$ & $\begin{array}{l}0.0499 \\
0.0020 \\
0.0072 \\
n s \\
0.0350 \\
k \star \\
k * \\
k \star\end{array}$ & $\begin{array}{l}0.0114 \\
0.0006 \\
0.0003 \\
0.0045 \\
0.0048 \\
0.0012 \\
0.0002 \\
\star \star\end{array}$ \\
\hline Pescados y mariscos frescos & 0.0173 & 0.0296 & 0.0089 & ** & 0.0033 & 0.0052 \\
\hline Pescados y mariscos procesados & 0.0062 & ** & ns & ** & ns. & 0.0022 \\
\hline $\begin{array}{l}\text { Otros alimentos } \\
\text { Soya } \\
\text { Especias y aderezos } \\
\text { Café tostado o molido } \\
\text { Carê Boluble o instantáneo } \\
\text { Chocolate, cocos y tê } \\
\text { Alinentos preparados para niños } \\
\text { Bebidas slcohólicas } \\
\text { Semillas }\end{array}$ & $\begin{array}{c}0.0475 \\
* * \\
0.0063 \\
n s \\
* k \\
k \star \\
* k \\
0.0400 \\
* *\end{array}$ & $\begin{array}{c}0.0542 \\
* * \\
0.0045 \\
n s \\
k * \\
k * \\
* * \\
* k \\
k *\end{array}$ & $\begin{array}{c}0.0489 \\
* * \\
0.0045 \\
0.0030 \\
0.0011 \\
0.0015 \\
* * \\
\text { ns } \\
* *\end{array}$ & $\begin{array}{c}0.0800 \\
* k \\
k * \\
k * \\
k * \\
k k \\
k k \\
k * \\
k *\end{array}$ & $\begin{array}{c}0.0832 \\
\star * \\
0.0093 \\
0.0049 \\
0.0096 \\
0.0023 \\
\star * \\
n 8 \\
\star *\end{array}$ & $\begin{array}{l}0.0242 \\
* \star \\
0.0030 \\
0.0014 \\
0.0028 \\
0.0017 \\
0.0006 \\
0.0083 \\
0.0004\end{array}$ \\
\hline Alimentos consumidos fuera del hogar & 0.0096 & ** & 0.0327 & ** & 0.0655 & 0.0461 \\
\hline Prueba de Agregacín & 1.0342 & 1.0372 & 1.0594 & 0.9731 & 1.0951 & 1.0134 \\
\hline
\end{tabular}

Fuente: Secretaría de Programaciôn y Presupuesto, Coordinaciốn General del Sistema Nacional de Informaciôn, "Encuesta Nacional de Ingresos y Gastos de los Hoga-
res, 1977". **: datos insuficientes ns: coéziciente de regresiôn no significativo t: reaultados incoherentes

ota: El mếtodo usado para calcular las propensiones estă en la Seccibn A.2 del Apếndice Metodologico.

(1) Estas propensiones fueron ajustadas para mejorar la prueba de agregaciôn y cener un valor mắs acorde con el comportamiento del resto. 
Cuadro 11

Propension marginal al consumo por regiones agrupadas

\begin{tabular}{|c|c|c|}
\hline & $\begin{array}{l}Y \leq 1 \mathrm{SM} \\
\text { Regi6n } \\
4,5 \text { y } 8\end{array}$ & $\begin{array}{l}\mathrm{Y} \leq 1 \mathrm{SM} \\
\text { Resto de las } \\
\text { Regiones }\end{array}$ \\
\hline $\begin{array}{l}\text { Tortillas de maíz } \\
\text { Malz en grano } \\
\text { Pan dulce, de caja y otros panes } \\
\text { Pastas para sopa }\end{array}$ & $\begin{array}{l}0.0183 \\
0.0252 \\
0.0238 \\
0.0096\end{array}$ & $\begin{array}{l}0.0327 \\
0.0065 \\
0.0143 \\
0.0094\end{array}$ \\
\hline Arroz & 0.0137 & 0.0129 \\
\hline $\begin{array}{l}\text { Carne de res } \\
\text { Carne de puerco } \\
\text { Carne de aves }\end{array}$ & $\begin{array}{l}0.0353 \\
0.0135 \\
0.0074\end{array}$ & $\begin{array}{l}0.0505 \\
0.0129 \\
0.0098\end{array}$ \\
\hline Aceites y grasas vegetales & 0.0174 & 0.0284 \\
\hline $\begin{array}{l}\text { Leche bronca } \\
\text { Leche pasteurizada } \\
\text { Queso fresco }\end{array}$ & $\begin{array}{l}0.0252 \\
0.0000 \\
0.0033\end{array}$ & $\begin{array}{l}0.0092 \\
0.0231 \\
0.0045\end{array}$ \\
\hline Huevo & 0.0197 & 0.0221 \\
\hline $\begin{array}{l}\text { Prijol } \\
\text { Tomate fresco } \\
\text { Papa } \\
\text { Plátano }\end{array}$ & $\begin{array}{l}0.0328 \\
0.0145 \\
.0 .0043 \\
0.0037\end{array}$ & $\begin{array}{l}0.0227 \\
0.0137 \\
0.0089 \\
0.0036\end{array}$ \\
\hline $\begin{array}{l}\text { Azúcar blanca } \\
\text { AzǴar roorena } \\
\text { Refrescos y sodas }\end{array}$ & $\begin{array}{l}0.0064 \\
0.0039 \\
0.0155\end{array}$ & $\begin{array}{l}0.0020 \\
0.0046 \\
0.0359\end{array}$ \\
\hline $\begin{array}{l}\text { Café tostado o molido } \\
\text { café soluble o instantáneo } \\
\text { Bebidas alcohólicas }\end{array}$ & $\begin{array}{l}0.0092 \\
0.0022 \\
0.0121\end{array}$ & $\begin{array}{l}0.0193 \\
0.0040 \\
0.0000\end{array}$ \\
\hline Alimentos $y$ bebidas & 0.6294 & 0.5685 \\
\hline $\begin{array}{l}\text { Vestimenta y calzado } \\
\text { Vivienda } \\
\text { Educación } \\
\text { Salud } \\
\text { Transporte y comunicaciones } \\
\text { Otros gastos }\end{array}$ & $\begin{array}{l}0.0708 \\
0.1011 \\
0.0124 \\
0.0314 \\
0.0279 \\
0.0989\end{array}$ & $\begin{array}{l}0.0800 \\
0.1700 \\
0.0099 \\
0.0334 \\
0.0580 \\
0.1444\end{array}$ \\
\hline
\end{tabular}

Fuente: Cuadro 10.

hogares, la demanda de prácticamente todos los productos alimenticios aumentaría más que bajo una distribución constante excepto en los casos de otros tipos de carne y carnes procesadas, cítricos, otras frutas frescas, jugos o néctares, pescados y mariscos procesados, alimentos preparados para niños, bebidas alcohólicas y alimentos consumidos fuera del hogar. Es decir, parte de la agroindustria moderna y también los servicios de restaurantes, serf́an los más afectados por una redistribución del ingreso porque se enfrentarían a un mercado relativamente más pequeño.

Por otra parte, los incrementos más fuertes se presentan en tortillas de maíz, productos derivados del trigo, arroz, carne de res y de puerco, leche y derivados, huevos, legumbres y hortalizas, y refrescos y sodas. O sea, una redistribución del ingreso presionaría sobre la oferta de no sólo los cereales básicos, sino también sobre la de productos de origen animal (carne, leche y huevos), y de origen vegetal de todo tipo. 
El experimento seleccionado a nivel regional consiste en suponer una redistribución del ingreso hacia el grupo de hasta un salario mínimo de las regiones más pobres: 4,5 y 8 . Las propensiones marginales agrupadas para ciertos productos seleccionados aparecen en el cuadro 11.

En el cuadro mencionado se observa que, en la medida en que el ingreso per cápita del grupo más pobre de estas regiones, aumentara en un monto mayor que el del grupo objetivo del resto de las regiones, la demanda de maíz en grano, pan dulce, de caja y otros panes, arroz, carne de puerco, leche bronca, frijol, tomate y azúcar blanca, subiría relativamente más que si la redistribución fuera la misma para los hogares pobres de todas las regiones. En contraste, la demanda principalmente de tortillas de maíz, carne de res, aceites y grasas vegetales, leche pasteurizada, huevos y refrescos y sodas, sería (relativamente) menor. Cuando se comparan estos resultados con los obtenidos en el experimentado a nivel nacional, inmediatamente se evidencia que en este último permanece oculta la heterogeneidad de los patrones de consumo regionales.

El resultado más importante experimentado por una redistribución a nivel regional es que la presión sobre la oferta de productos de origen animal, disminuye mucho cuando los aumentos de ingreso fluyen en mayor magnitud hacia las regiones más pobres; por otra parte, en este caso también sucede que la demanda de maíz en su forma más primaria (maíz en grano), recupera una posición relativa muy importante, que se diluye totalmente con la información agregada a nivel nacional.

\section{Requerimientos redistributivos}

En el cuadro 12 aparece el gasto en alimentos por región y grupo socioeconómico para 1977 (según la Encuesta de Ingresos y Gastos de los Hogares), y el gasto recomendado, calculado a partir de la Canasta Básica Recomendable propuesta por el Sistema Alimentario Mexicano que cumple con los requerimientos nutritivos ${ }^{23}$ (Cuadro 13). La diferencia entre ambas cantidades es la brecha que debe llenarse para que la población objetiva logre los mínimos de nutrición.

Una vez que se obtiene el incremento del gasto requerido en alimentos se puede deducir el aumento del ingreso necesario para lograr

\footnotetext{
23 Esta canasta fue elaborada por el Subproyecto No, 3 del Sistema Alimentario Me-
} xicano. 
Cuadro 12

Requerimtentos redistributivos y costo fiscal de la transferencia de ingresos y dal sistema de cupones: 1977.

\begin{tabular}{|c|c|c|c|c|c|c|c|c|c|}
\hline & (1) & (2) & (3) & (4) & (5) & (6) & (7) & (8) & (9) \\
\hline $\begin{array}{l}\text { Regiôn } \\
\text { yupo } \\
\text { Grupo }\end{array}$ & $\begin{array}{l}\text { Consumo } \\
\text { actual: } \\
\text { pe608 } \\
1977 *\end{array}$ & $\begin{array}{l}\text { Consumo } \\
\text { recomendado: } \\
\text { Peso6 1977* }\end{array}$ & $\begin{array}{c}\text { Dêficit: * } \\
\text { 1977 } \\
\text { absoluto }\end{array}$ & $\begin{array}{l}\text { Dêficit } \\
\quad \% \\
\text { (2) } /(1)\end{array}$ & $\begin{array}{l}\text { Elasticidad } \\
\text { gasto para } \\
\text { alimentos }\end{array}$ & $\begin{array}{l}\text { Incremento porcen } \\
\text { tual requerido en } \\
\text { el ingreso } \\
(4) /(5)\end{array}$ & 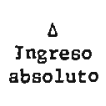 & $\begin{array}{c}\text { Ingreso total } \\
\text { requerido } \\
\text { (Mensual Per Cápita) }\end{array}$ & Años \\
\hline 1.1 & 7.54 & 10.40 & -2.86 & .3793 & 1.1397 & .3328 & 124.48 & 498.53 & 6.6 \\
\hline 1.2 & 12.46 & 10.40 & - & - & .7910 & - & - & - & - \\
\hline 2.1 & 7.12 & 9.69 & -2.57 & .3609 & 1.4669 & .2460 & 62.14 & 314.73 & 6.3 \\
\hline 2.2 & 12.05 & 9.69 & - & - & 1.3990 & - & - & - & - \\
\hline 3.1 & 6.76 & 10.18 & -3.42 & .5059 & 1.2681 & .3989 & 96.31 & 337.75 & 8.4 \\
\hline 3.2 & 9.74 & 10.18 & -0.44 & .0451 & 1.1753 & .0530 & 19.53 & 388.08 & 1.0 \\
\hline 4.1 & 5.41 & 10.09 & -4.68 & .8650 & 1.2424 & .6962 & 148.85 & 362.65 & 12.8 \\
\hline 4.2 & 6.84 & 10.09 & -3.25 & .4751 & 1.1397 & .4169 & 133.86 & 454.94 & 8.0 \\
\hline 5.1 & 3.59 & 9.84 & -6.25 & 1.7409 & 1.0244 & 1.6994 & 222.91 & 413.44 & 20.7 \\
\hline 5.2 & 7.22 & 9.84 & -2.62 & .3628 & 1.1786 & .3078 & 87.53 & 371.91 & 6.34 \\
\hline 6.1 & 6.44 & 10.20 & -3.76 & .5838 & 1.0334 & .5649 & 127.50 & 353.20 & 9,42 \\
\hline 6.2 & 8.72 & 10.20 & -1.48 & .1697 & .9364 & .1812 & 64.88 & 422.93 & 3.21 \\
\hline 7.1 & 6.35 & 10.36 & -4.01 & .6314 & 1.1999 & .5262 & 116.32 & 337.38 & 10.03 \\
\hline 7.2 & 8.83 & 10.36 & -1.53 & .1732 & .9631 & . 1798 & 69.54 & 456.33 & 3.27 \\
\hline 8.1 & 6.10 & 9.86 & -3.76 & .6163 & 1.2265 & .5025 & 101.58 & 303.72 & 9.84 \\
\hline 8.2 & 9.27 & 9.86 & -0.59 & .0636 & .9371 & .0679 & 22.16 & 348.51 & 1.26 \\
\hline 9.1 & 8.61 & 10.37 & -1.76 & .2044 & .7472 & .2736 & 106.93 & 497.75 & 3.8 \\
\hline 9.2 & 10.31 & 10.37 & -0.06 & .0058 & 1.0858 & .0053 & 2.72 & $515.52^{\circ}$ & .12 \\
\hline
\end{tabular}

Secretaría de Programación y Prgsupuesto, Coordinación General
Ingresos y Gastos de los Hogares, 1977. Informe Metodologico".

" Pesos per cấpita diarios; no incluye ni bebidas alcohólicas ni refrescos; 1ncluye autoconsumo.

(9) Se calculö con la förmula $Y_{1}=Y_{0}(1+r)^{t}$

T.I.: Transferencia de ingresos

c: cupones 
este incremento, ${ }^{24}$ cifra que también aparece en el Cuadro 12. Como era de esperarse, en las regiones más pobres $(4,5,6,7$ y 8$)$ el ingreso debe aumentar en una proporción mayor, que llega a ser de hasta $170 \%$ en la región 5-agrícola, por ejemplo.

Bajo el supuesto optimista de un crecimiento del ingreso per cápita homogéneo para todos los grupos (distribución del ingreso constante), e igual al $5 \%, 25$ el grupo de bajos ingresos de las regiones 4 y 5 , por ejemplo, deberían esperar alrededor de 12.8 y 20.7 años, respectivamente, para alcanzar el nivel de ingresos necesario, para cubrir el gasto en alimentos implicado por la Canasta Básica Recomendable.

Es pertinente, sin embargo, hacer dos aclaraciones importantes. En primer lugar, los requerimientos de incrementos en el ingreso se refiere a cambios en términos reales y suponen constante la estructura de precios relativos. Un encarecimiento de los alimentos, obviamente, implicaría -además de la necesidad de tomar en cuenta los efectos de la elasticidad-precio- un nivel de gasto en alimentos y, por tanto, del ingreso mayor; o sea, la redistribución del ingreso requerido sería también mayor. En segundo lugar, aquí hemos calculado el incremento del ingreso requerido para mantener un nivel de gasto según lo propone la Canasta Básica Recomendable, pero sin fijarnos en su estructura. De hecho en principio, no hay por qué pensar que los hogares distribuyen el gasto destinado a los alimentos en la forma recomendada, ya que sus hábitos pueden ser distintos. ${ }^{26}$ Es por ello que una redistribución del ingreso por sí sola no es garantía de una alimentación adecuada cuando la redistribución es tal que sólo se aproxima a cubrir minimos. De ahí la necesidad de establecer mecanismos complementarios para contribuir a una asignación del gasto en alimentos que sea más "eficiente" en términos de nutrientes.

De cualquier forma, estos experimentos sencillos permiten corroborar la necesidad inaplazable de modificar la situación distributiva y/o del consumo en favor de los sectores más pobres para que la condición alimentaria de estos grupos mejore y que esta mejora suceda en un plazo breve. Dada la inserción en la estructura productiva de los lugares más pobres, se desprende que esta redistribución debe darse - principalmente- hacia el campesinado y los jornaleros, en el sector rural, y hacia aquellos que forman parte del sector "in-

24 Se trata, en realidad, del aumento necesario del gasto total y se calcula divjdjendo el incremento requerido del gasto, entre la propensión marginal al consumo correspondiente.

25 Esta tasa de crecjmiento es una de las más optimistas, ya que supone un crecimiento del ingreso global del $8 \%$ y $3 \%$ para la población.

26 Además, tiene mucha importancia qué integrante de la familia recibe el incremento del ingreso y quién toma las decisiones respecto a su destino. 
Cuadro 13

Canasta basica recomendable

\begin{tabular}{|c|c|c|c|c|}
\hline Producto & $\begin{array}{c}\text { C.B.R. } \\
\text { Ingesta Neta grs. } \\
\text { p/capita diarios }\end{array}$ & $\begin{array}{c}\text { Porcion } \\
\text { Comestible }\end{array}$ & $\begin{array}{l}\text { C.B.R. } \\
\text { Grs. Brutos por } \\
\text { cápita diarios }\end{array}$ & Por ciento \\
\hline Cereales & 603.33 & & & \\
\hline MaIz & 497.19 & & 516.45 & 43.74 \\
\hline$\overline{\mathrm{MaSz}}$ en grano & 221.48 & 0.92 & 240.74 & 20.39 \\
\hline Tortillas & 268.25 & 1.0 & 268.25 & 22.72 \\
\hline Masa & 7.46 & 1.0 & 7.46 & .63 \\
\hline Trigo & 88.14 & & 106.14 & 9.0 \\
\hline Harina de trigo & 16.60 & 1.0 & 16.6 & 1.41 \\
\hline Pan dulce & 16.78 & 1.0 & 16.78 & 1.42 \\
\hline Pan blanco & 30.00 & 1.0 & 30.0 & 2.54 \\
\hline Galletas & 8.76 & 1.0 & 8.76 & .75 \\
\hline Pastas & 16.00 & 1.0 & 16.0 & 1.36 \\
\hline Arroz & 18.00 & 1.0 & 18.0 & 1.52 \\
\hline Leguminosas & 52.00 & & 52.00 & 4.40 \\
\hline Frijol & 52.0 & 1.0 & 52.0 & 4.40 \\
\hline Feculantes & 23.04 & & 28.1 & 2.38 \\
\hline Papa & 23.04 & 0.82 & 28.1 & 2.38 \\
\hline Verduras & 35.59 & & 40.9 & 3.46 \\
\hline Jitomate & 30.18 & 0.88 & 34.3 & 2.91 \\
\hline Chile & 1.82 & 0.91 & 2.0 & .17 \\
\hline cebol1a & 2.66 & 0.86 & 3.1 & .26 \\
\hline Lechuga & 0.24 & 0.62 & 0.4 & .03 \\
\hline Zanahoria & 0.69 & 0.63 & 1.1 & .09 \\
\hline Frutas & 41.53 & & 63.9 & 5.41 \\
\hline Plátano & 17.88 & 0.68 & 26.3 & 2.23 \\
\hline Manzana & 0.93 & 0.67 & 1.4 & .12 \\
\hline Limon & 4.77 & 0.62 & 7.7 & .65 \\
\hline Naranja & 17.95 & 0.63 & 28.5 & 2.41 \\
\hline Productos Origen AnImal & 278.58 & & 306.0 & 25.94 \\
\hline Carne de res & 13.11 & 0.69 & 19.0 & 1.61 \\
\hline Carne de puerco & 7.10 & 0.71 & 10.0 & .81 \\
\hline Carne de ave & 6.72 & 0.56 & 12.0 & 1.02 \\
\hline Carne de ovic. & 5.46 & 0.78 & 7.0 & .60 \\
\hline Huevo & 25.52 & 0.88 & 29.0 & 2.46 \\
\hline Leche fresca & 210.00 & 1.0 & 210.0 & 17.79 \\
\hline Manteca de puerco & 2.00 & 1.0 & 2.0 & .17 \\
\hline Pescados y mariscos & 8.67 & 0.51 & 17.0 & 1.44 \\
\hline $\begin{array}{l}\text { Otros } \\
\text { otros }\end{array}$ & 67.00 & & 67.00 & 5.67 \\
\hline Aceite vegetal & 17.00 & 1.0 & 17.0 & 1.44 \\
\hline AzGacar & 50.00 & 1.0 & 50.0 & 4.23 \\
\hline Total & $1,101.07$ & & $1,180.49$ & 100.00 \\
\hline
\end{tabular}

Fuente: oficina de Asesores del C. Presidente de la Repáblica, Sistema Alimentario Mexicano. 
formal" en las áreas urbanas. De ahr que las políticas y tendencias que mejoren su situación en el proceso de generación y apropiación del excedente -desde cambios en la estructura de la propiedad, modificación en los términos de intercambio en favor de la producción agrícola en manos del campesinado, generación de un mayor número de empleos, subsidios directos al consumo de productos específicos, etc.- contribuirían a mejorar las condiciones de estos sectores.

\section{APENDICE METODOLOGICO}

\section{Metodología para calcular las elasticidades-gasto y propensiones marginales al consumo}

\section{i) Método}

Para calcular las elasticidades-gasto y las propensiones marginales al consumo se procedió en tres etapas.

Primero se estimaron elasticidades-ingreso por bien, grupo y región, y para los totales nacionales con mínimos cuadrados generalizados. Se prefirió usar este método, en lugar de los mínimos cuadrados ordinarios porque las regresiones se estimaron a partir de datos agrupados. 27,28

En segundo lugar, se estimaron las elasticidades-gasto dividiendo el coeficiente de elasticidad-ingreso obtenido para cada producto entre el coeficiente de elasticidad-ingreso del gasto total. ${ }^{29}$ Este método de estimación, llamado de "variables instrumentales", se recomienda en aquellos casos en que se sabe que las variables utilizadas tienen errores de medición. En la ENIG 77, tanto los consumos como los ingresos, deben estar medidos con error; en estos casos se recomienda estimar la elasticidad-gasto con la variable ingreso como instrumento en lugar de usar como variable explicativa directamente el gasto total. 30

27 Es sabido que cuando se hacen estimaciones a partir de promedios (datos agrupados), en lugar de las observaciones directas, a menos que el número de casos en cada promedio sea cl mismo, existe el peligro de introducir heterocedasticidad. Por lo tanto, cada promedio se ponderó por la participación relativa de las observaciones de éste en el total de observaciones del grupo y, para estimar las regresiones se usaron los promedios ponderados, o sea, el método de mínimos cuadrados generalizados (Cramer, J. S., 1973, Econometría Empírica, Fondo de Cultura Económica, México; pp. 144-146).

28 Los resultados empíricos en detalle de estas estimaciones pueden obtenerse directamente de la autora.

29 Las elasticidades-gasto estimadas, están en el Cuadro 10 del tex to.

30 Véase Goreux, L. M. Boletín Mensual de Economia y Estadística Agricolas, FAO, Vol. IX, No. 10, octubre, 1960. 
En tercer lugar, las propensiones marginales al consumo se calculaIon multiplicando las elasticidades-gasto del bien i por la participación del consumo en el bien $i$, en relación al consumo total (o propensión media al consumo del bien i). ${ }^{31}, 32$

\section{ii) Forma de la función y variables, explicada y explicativa}

La forma funcional por la que se optó aquí es la doble-logarítmica (o log-línea). Esta selección se hizo por varias razones: por un lado, ésta es una forma bastante flexible, que permite representar comportamientos diversos al admitir curvaturas en la trayectoria de las observaciones utilizadas; por otro, permite obtener estimaciones de la elasticidad independientemente de la unidad en que se miden las variables;33 y, por último, su manejo econométrico es sumamente simple. ${ }^{34}$

En términos algebraicos las funciones que se estimaron son las siguientes:

$$
\begin{aligned}
& \log g_{i}=a_{i}+b_{i} \log y+e, \quad \text { para todos } \operatorname{los} i \\
& \log g=a^{\prime}+b^{\prime} \log y+e^{\prime}
\end{aligned}
$$

donde $\mathrm{g}_{\mathrm{j}}$ es el gasto per cápita (ponderado) en el bien i; "Y", el ingreso per cápita (ponderado); $\mathrm{y}, \mathrm{g}$, el gasto total per cápita (ponderado). ${ }^{35}$ Como se dijo en la sección $i$, a elasticidad-gasto $\left(c_{i}\right)$, es igual $\mathrm{a} \overline{\mathrm{c}} \mathrm{i}=\overline{\mathrm{b}} \mathrm{i} / \mathrm{b}: 36$

31 Es muy sencillo demostrar que la fórmula para calcular la propensión marginal al consumo es igual $a: b ;(g ; G)$, donde $b ;$ es el coeficiente estimado de elasticidad-gasto del bien $i, g_{j}$ es el gasto en $;$ y G el gasto total. Esta fórmula se comprueba inmediatamente si se expresa a la elasticidad como la relación entre la propensión marginal y la media:

$$
\overrightarrow{\mathrm{b}}=(\mathrm{dg} ; / \mathrm{dg}) /(\mathrm{g} ; / \mathrm{G})
$$

32 Los resultados aparecen en los Cuadros 9 y 10 del tex to.

33 Es decir que la elasticidad-gasto en términos monetarios es igual a la elasticidad-consumo en términos físicos.

34 Esta razón tiene mucho, pero si se considera que se estimaron, en total, dos mil doscientos veinte regresiones.

35 Lo ideal hubiera sido poder medir las variables explicadas y explicativas en términos per cápita, pero con los miembros del hogar convertidos en unidades equivalentes. Sin embargo, inicialmente no se contó con la información necesaria y, además, hacer esta conversión, habría sido muy complicado porque para efectuarla, los coeficientes deberían variar con el bien. En nuestra estimación, en realidad, al usar las variables en términos per cópita sin conversión se consideró el supuesto implícito de que no existen economías ni deseconomías de escala en relación a la composición del hogar.

36 El guión encima del símbolo significa que se trata de los coeficientes estimados. 


\section{iii) Agrupamiento de los hogares}

La información total de la ENIG '77 (gasto, ingreso, población y características socioeconómicas) se dividió en nueve regiones, y en tres grupos socioeconómicos dentro de cada región. La regionalización seleccionada es la que se utilizó en la ENIG ' 77 con excepción de una (la región nueve) donde se agruparon los datos de las áreas metropolitanas de México, Monterrey y Guadalajara. Los grupos socioeconómicos dentro de cada región se formaron según las veces del Salario Mínimo General regional que representaba el ingreso del hogar y el tipo de actividad desempeñada por el jefe del hogar: el primer grupo se constituye por aquellos hogares que percibieron hasta una vez el Salario Mínimo regional inclusive, y que además el jefe del hogar desempeñaba una actividad del tipo agrícola; el segundo grupo se constituyó por aquellos hogares que teniendo las mismas características de ingreso que el grupo anterior, el jefe del hogar desempeñó cualquier tipo de actividad distinta a las que se consideraron como agrícolas, ${ }^{37}$ el tercer grupo socioeconómico está formado por todos los hogares que dentro de la región respectiva percibieron un ingreso superior al Salario Mínimo regional. Las entidades federativas (y áreas metropolitanas) que componen cada región y los salarios regionales correspondientes están en el Cuadro 3.

Además de estimar las regresiones a nivel regional, se hizo un ejercicio análogo a nivel nacional, para el grupo de hasta un salario mínimo y para el resto, ${ }^{38}$ y para el total de la población.

En total, las estimaciones se hicieron para treinta grupos socioeconómicos: veintisiete grupos a nivel de regiones y tres a nivel nacional. ${ }^{39}$

\footnotetext{
37 Las actividades que se incluyeron dentro del grupo agrícola son: Agricultura, Ganadería, Avicultura, Silvicultura, Pesca, Combinación Agropecuaria, Otras Actividades Agropecuarias y, las Actividades Agsopecuarias insuficientemente especificadas.

38 Para definir los grupos de ingreso se utilizó el salario mínimo correspondiente a cada región, en lugar de un promedio nacional.

39 Es decir, se calcularon regresiones para 73 productos, más la regresión para estimar la elasticidad-ingreso del gasto total (o sea, 74 regresiones en total), para los 30 grupos de hogares que ya mencionamos; el número total de regresiones, entonces, asciende a 2200 . Los resultados pueden obtenerse directamente con la autora.
} 